\title{
The Local Characteristics of Indonesian Seas and Its Possible Connection with ENSO and IOD: Ten Years Analysis of Satellite Remote Sensing Data
}

\author{
I Dewa Nyoman Nurweda Putra ${ }^{1,2} \&$ Tasuku Tanaka ${ }^{1}$ \\ ${ }^{1}$ Graduate School of Science and Engineering, University of Yamaguchi, Yamaguchi Ken, Ube Shi Tokiwadai, \\ Japan \\ ${ }^{2}$ University of Udayana, Bali, Indonesia \\ Correspondence: I Dewa Nyoman Nurweda Putra, Graduate School of Science and Engineering, University of \\ Yamaguchi, 755-8611 Yamaguchi Ken, Ube Shi Tokiwadai 2-16-1, Japan. Tel: 81-836-859-129; Center for \\ Remote Sensing and Ocean Science (CReSOS), University of Udayana, PB Sudirman Street, Denpasar 80232, \\ Bali, Indonesia. Tel: 62-361-256-162. E-mail: mangnik14@yahoo.co.id
}

Received: April 26, 2013 Accepted: May 23, 2013 Online Published: June 24, 2013

doi: 10.5539/esr.v2n2p153 URL: http://dx.doi.org/10.5539/esr.v2n2p153

\begin{abstract}
The overall objective of this study is to investigate the local characteristics of the Indonesian Seas in response to the 6 months, seasonal and inter-annual variations. A moving averages method with 3, 6 and 12 months of lengths has been used to show the temporal variability. Using satellite observed datasets for the 10 year period from December 1999-November 2009, the results of moving averages indicate the 6 months and seasonal variabilities of sea surface temperature (SST), zonal-component of wind speed (U-WS) and rain rate (RR) in most of the Indonesian Seas area. It is also interesting to note that, although in the same latitude with the strong seasonal variability area, a stable condition of SST occurs in some particular areas. The cross-lag correlation analysis shows the relationship among indices with several month time lags. After removing the seasonal variability, the possible connection of indices with the El Nino-Southern Oscillation (ENSO) and the Indian Ocean Dipole (IOD) phenomena in the Indonesian Seas can be detected by the 6 month moving averages method.
\end{abstract}

Keywords: Indonesian Seas, seasonal variability, 6-months variability, moving averages, ENSO, IOD

\section{Introduction}

The Indonesian Seas, a semi-closed marginal sea, separates the Pacific Ocean from the Indian Ocean (see Figure 1) with a chain of big and small islands. The bathymetry is generally shallow $(<100 \mathrm{~m})$ throughout the western area of the inner Indonesian Seas, while the abyssal sea basin in the east of the inner Indonesian Seas has the depths of $5000 \mathrm{~m}$. The Indonesian Seas lie on and near the Equator including "warm pool" with its high temperature. The region also has an important pathway for water transport (Gordon et al., 2003, 2010; Sprintall et al., 2004; Gordon, 2005), the Indonesian throughflow (ITF). ITF affects both the regional circulation and thermal structure (Godfrey 1996; England \& Huang, 2005).

The general characteristic of the Indonesian seas was reported with the satellite remote-sensing dataset (Swardika et al., 2012). It concluded that the ocean characteristics, the sea surface temperature (SST), zonal-component of wind speed (U-WS) and rain rate (RR), are very stable in the Equatorial areas, while their seasonal variability appears as increasing the latitude in both the north and south hemispheres. The two abnormal ocean phenomena have been studied since the 1990s: the El Nino-Southern Oscillation (ENSO) and the Indian Ocean Dipole (IOD). ENSO is the anomaly of the wide weather system including ocean, atmosphere and land. Its indicator, or the ENSO index, is the SST in the central tropical Pacific Ocean (Trenberth et al., 1998; Diaz et al., 2001; Li et al., 2010; Weng et al., 2009; Pradhan et al., 2011). IOD is the similar phenomenon as ENSO and its indicator is the SST difference between the eastern and western tropical Indian Ocean (Saji \& Yamagata, 2003; Weng et al., 2009; Luo et al., 2010). It is of great interest whether the ENSO and IOD affect the local characteristics of the Indonesian Seas.

The aim of this study is to analyse the ocean characteristics and to show the temporal variability of ocean 
characters for the local areas in the Indonesian Seas. Then, we compare those temporal variabilities with the ENSO and IOD indices to consider their influence to the Indonesian Seas. We also show the locality of those variabilities and the correlation of indices.

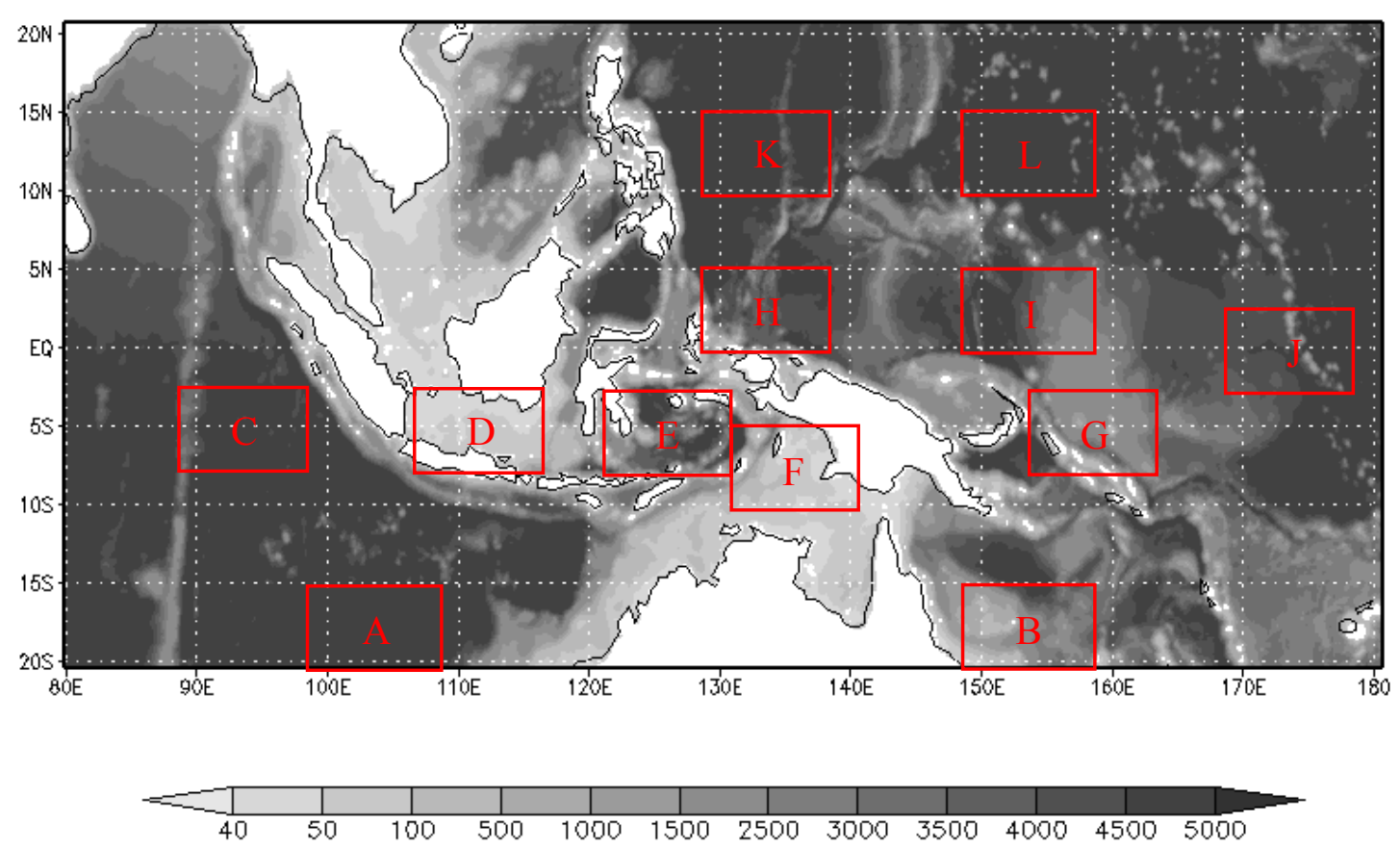

Figure 1. The bottom topography map (scale in meter) of the Indonesian Seas derived from ETOPO 2 minutes (Smith and Sandwell 1997).

Axes indicate longitude $80^{\circ}-180^{\circ} \mathrm{E}$ and latitude $20^{\circ} \mathrm{S}-20^{\circ} \mathrm{N}$. Areas with deep water are shaded in light grey, areas with shallow water are shaded in dark grey and areas with no available data are in white

\section{Method of Analysis}

We reveal the ocean characteristics from the monthly SST, U-WS and RR in 10 years (December 1999 November 2009) by satellites observation. Those three data show the clear cyclic variability of the ocean characteristics (Swardika et al., 2012; Nurweda \& Tanaka, 2012).

To determine the local variability, we calculate the average of the indices over each local area from the monthly grid data, which is downloaded from the satellite data archives. In order to analyse the temporal variability of indices in the Indonesian Seas, we need to take account of the 6 months variability because the solar looking angle becomes at zenith twice a year.

To detect the seasonal variability, we calculate the 6 months moving averages in which no 6 months variability appears. If there exists a longer than 12 months cyclic variability, it appears in the 12 months moving averages. We should know whether those longer cyclic variabilities exist. Thus we calculate the 6 and 12 months moving averages.

To detect the 6 months variability, we calculate the 3 months moving averages. If a seasonal variability exists, it also appears in the 6 months moving averages. But we can distinguish the 6 months variability from the seasonal variability by carefully expecting the average.

The moving averages for the month- $i$ are calculated as follows:

$$
\begin{gathered}
X_{i}=\frac{1}{2 k}\left[\sum_{j=-(k-1)}^{k-1} x_{i+j}+\frac{1}{2}\left(x_{i-k}+x_{i+k}\right)\right] \quad ; k=3 \text { for the } 6 \text { months moving averages } \\
; k=6 \text { for the } 12 \text { months moving averages } \\
X_{i}=\frac{1}{3 k}\left[\sum_{j=-k}^{k} x_{i+j}\right] ; k=1 \text { for the } 3 \text { months moving averages }
\end{gathered}
$$


where $x_{i}$ is the original monthly data and $X_{i}$ is the monthly data of the moving averages. The value of $X_{i}$ corresponds to the middle of the month.

The ENSO index is defined with the 3 months moving averages of SST in the central tropical Pacific Ocean. If we compare the indices in the Indonesian Seas with the ENSO index, we should take account of both 6 months and seasonal variabilities. As we will show later, all the indices in the ENSO Index area have neither 6 months nor seasonal variabilities. For the comparison, we need the indices free from the 6 months and seasonal variabilities. Thus, the connections of indices with the ENSO signal are observed by the 6 months moving averages of the deseasonalized indices. The deseasonalized $\left(d_{i}\right)$ indices can be calculated as follows:

$$
d_{i}=W_{i}-S_{i} \quad ; i=1,2,3, \ldots, N
$$

where:

$$
W_{i}=x_{i}-X_{i}
$$

$W_{i}$ is the monthly data with no temporal variability longer than 12 months; $x_{i}$ is the original monthly data and $X_{i}$ is calculated by the Equation 1 with $k=6$.

$$
\begin{gathered}
S_{i}=P_{i}-\bar{P} ; \quad i=1,2,3, \ldots, N \\
P_{a+j * 12}=\frac{W_{a}+W_{a+12}+W_{a+2 * 12}+\cdots+W_{a+b * 12}}{(b+1)} \\
; \quad a=1,2,3, \cdots, 12 \\
; j=0,1,2, \cdots, b \\
; \quad j \text { is increased repeatedly for every " } a " \\
; \quad b=\frac{N}{12}-1 \\
\bar{P}=\frac{1}{N} \sum_{i=1}^{N} P_{i}
\end{gathered}
$$

We also calculate the auto-correlation of SST, U-WS and RR in order to analyse the temporal variability of indices. The auto-correlation function $\left(R_{x x}\right)$ is expressed as follows:

$$
R_{x x}(\tau)=\frac{c_{x x}(\tau)}{\sigma^{2}}
$$

where:

$$
\begin{gathered}
C_{x x}(\tau)=\frac{1}{N-k} \sum_{i=1}^{(N-k)}\left[x_{i}-\overline{x_{l}}\right]\left[x_{i+k}-\overline{x_{l+k}}\right] ; \quad k=\tau \Delta t \\
\overline{x_{l}}=\frac{1}{N-k} \sum_{i=1}^{N-k} x_{i} \text { and } \overline{x_{l+k}}=\frac{1}{N-k} \sum_{i=(k+1)}^{N} x_{i} \\
\sigma^{2}=\frac{1}{N-k} \sum_{i=1}^{N-k}\left[\mathrm{x}_{i}-\bar{x}\right]^{2} \quad \text { and } \quad \bar{x}=\frac{1}{N-k} \sum_{i=1}^{N-k} x_{i}
\end{gathered}
$$

To identify the relationship among the indices, the cross-correlation is calculated. The cross-correlation $\left(R_{x y}\right)$ is expressed as follows:

$$
R_{x y}(\tau)=\frac{C_{x y}(\tau)}{\sigma_{\mathrm{x}} \sigma_{\mathrm{y}}}
$$

where:

$$
C_{x y}(\tau)=\frac{1}{N-k} \sum_{i=1}^{(N-k)}\left[y_{i}-\bar{y}_{l}\right]\left[x_{i+k}-\overline{x_{l+k}}\right] ; \quad k=\tau \Delta t
$$




$$
\begin{gathered}
\bar{y}_{l}=\frac{1}{N-k} \sum_{i=1}^{N-k} y_{i} \quad \text { and } \quad \overline{x_{l+k}}=\frac{1}{N-k} \sum_{i=(k+1)}^{N} x_{i} \\
\sigma_{\mathrm{x}}^{2}=\frac{1}{N-k} \sum_{i=1}^{N-k}\left[\mathrm{x}_{i}-\bar{x}\right]^{2} \quad \text { and } \sigma_{\mathrm{y}}{ }^{2}=\frac{1}{N-k} \sum_{i=1}^{N-k}\left[y_{i}-\bar{y}\right]^{2} \\
\bar{x}=\frac{1}{N-k} \sum_{i=1}^{N-k} x_{i} \text { and } \bar{y}=\frac{1}{N-k} \sum_{i=1}^{N-k} y_{i}
\end{gathered}
$$

\section{Dataset}

We use the monthly data of SST and U-WS that are compiled by the Remote Sensing Systems (REMSS) from TRMM-TMI and QuikSCAT dataset in the $0.25^{\circ} \times 0.25^{\circ}$ grid (ftp://ftp.remss.com). The physical dimension of SST and UWS are [deg. Celsius] and [m/s], respectively. For precipitation, we use the TRMM combined level 3 (3B43) versions 6 data, which is compiled and supplied by the Earth Observation Research Center, Japan Aerospace Exploration Agency (JAXA EORC). The 3B43 version 6 data is recorded monthly in $0.25^{\circ}$ grid of horizontal resolution, and its physical dimension is [ $\mathrm{mm} / \mathrm{month}]$.

For the ENSO and IOD phenomena, the Ocean Nino Index (ONI) and Dipole Mode Index (DMI) are used (see Table 1 for the complete definition of the indices). The time series dataset of indices are prepared by National Oceanic and Atmospheric Administration (NOAA) - Climate Prediction Center (CPC) for the ONI dataset and

\begin{tabular}{|c|c|c|}
\hline Index & Area Boundary & Definition \\
\hline ONI & $5^{\circ} \mathrm{S}-5^{\circ} \mathrm{N}$ and $170^{\circ} \mathrm{W}-120^{\circ} \mathrm{W}$ & $\begin{array}{l}\text { El Nino: The } 3 \text { months moving averages of SST is at } \\
\text { least } 0.5 \text { warmer than } 30 \text {-year (1981-2010) average. } \\
\text { La Nina: The } 3 \text { months moving averages of SST is at } \\
\text { least } 0.5 \text { cooler than } 30 \text {-year (1981-2010) average. }\end{array}$ \\
\hline DMI & $\begin{array}{l}\text { Western Temperature of Indian Ocean (WTIO): } \\
10^{\circ} \mathrm{S}-10^{\circ} \mathrm{N} \text { and } 50^{\circ} \mathrm{E}-70^{\circ} \mathrm{E} \\
\text { South-eastern Temperature of Indian Ocean } \\
\text { (SETIO): } 10^{\circ} \mathrm{S}-0^{\circ} \text { and } 90^{\circ} \mathrm{E}-110^{\circ} \mathrm{E} \text { (Saji et al., } \\
\text { 1999) }\end{array}$ & $\begin{array}{l}\text { Positive IOD: The different of WTIO and SETIO is } \\
\text { warmer than 30-year (1971-2000) average. } \\
\text { Negative IOD: The different of WTIO and SETIO is } \\
\text { cooler than 30-year (1971-2000) average. }\end{array}$ \\
\hline
\end{tabular}
the Japan Agency for Marine-Earth Science and Technology (JAMSTEC) for the DMI dataset.

Table 1. Specifications of the SST anomaly index

We analyse the whole Indonesian Seas, from $80^{\circ}-180^{\circ} \mathrm{E}$ in longitude and from $20^{\circ} \mathrm{S}-20^{\circ} \mathrm{N}$ in latitude (see Figure 1), which spans the tropics of both Indian and Pacific Oceans. In order to analyze the local characteristics, the Indonesian Seas is divided into three regions with twelve areas. These three regions represent the south subtropical region, the near-equatorial region and the north subtropical region. The twelve local areas are (see Figure 1): area A covers the southeast Indian Ocean $\left(100^{\circ} \mathrm{E}-110^{\circ} \mathrm{E}, 20^{\circ} \mathrm{S}-15^{\circ} \mathrm{S}\right)$; area B covers the southwest Pacific Ocean $\left(150^{\circ} \mathrm{E}-160^{\circ} \mathrm{E}, 20^{\circ} \mathrm{S}-15^{\circ} \mathrm{S}\right)$; area C covers the Equatorial region of Indian Ocean $\left(90^{\circ} \mathrm{E}-100^{\circ}\right.$ $\left.\mathrm{E}, 7^{\circ} \mathrm{S}-2^{\circ} \mathrm{S}\right)$; area $\mathrm{D}\left(108^{\circ} \mathrm{E}-118^{\circ} \mathrm{E}, 7^{\circ} \mathrm{S}-2^{\circ} \mathrm{S}\right)$, area $\mathrm{E}\left(122^{\circ} \mathrm{E}-132^{\circ} \mathrm{E}, 7^{\circ} \mathrm{S}-2^{\circ} \mathrm{S}\right)$ and area $\mathrm{F}\left(132^{\circ} \mathrm{E}-\right.$ $\left.142^{\circ} \mathrm{E}, 10^{\circ} \mathrm{S}-5^{\circ} \mathrm{S}\right)$ cover the inner Indonesian Seas; area $\mathrm{G}\left(155^{\circ} \mathrm{E}-165^{\circ} \mathrm{E}, 7^{\circ} \mathrm{S}-2^{\circ} \mathrm{S}\right)$, area $\mathrm{H}\left(130^{\circ} \mathrm{E}-140^{\circ}\right.$ $\left.\mathrm{E}, 0^{\circ}-5^{\circ} \mathrm{N}\right)$ and area $\mathrm{I}\left(150^{\circ} \mathrm{E}-160^{\circ} \mathrm{E}, 0^{\circ}-5^{\circ} \mathrm{N}\right)$ cover the Equatorial region of Pacific Ocean; area $\mathrm{J}\left(170^{\circ} \mathrm{E}-\right.$ $\left.180^{\circ} \mathrm{E}, 3 \mathrm{~S}^{\circ}-3^{\circ} \mathrm{N}\right)$ covers the ENSO Index area; area $\mathrm{K}\left(130^{\circ} \mathrm{E}-140^{\circ} \mathrm{E}, 10^{\circ} \mathrm{N}-15^{\circ} \mathrm{N}\right)$ and area $\mathrm{L}\left(150^{\circ} \mathrm{E}-\right.$ $160^{\circ} \mathrm{E}, 10^{\circ} \mathrm{N}-15^{\circ} \mathrm{N}$ ) cover the northwest Pacific Ocean.

\section{Results and Discussion}

The 3, 6 and 12 months moving averages for all areas are shown in Figures 2 to 13. The summaries of the seasonal and 6 months variabilities are presented in Tables 2 and 3, respectively. The auto-correlation of indices is presented in Table 4. The correlation coefficients and time lag among indices are presented in Table 5.

The moving averages analysis shows that all indices in area $\mathrm{J}$ have neither 6 months nor seasonal variability (see Figures 11a, b and 20). The ENSO event is defined as the SST which stays for longer than 3 months outside the boundaries \pm 0.5 (see Figure 21). We summarise the El Nino and La Nina years in Tables 6 and 7 .

The 6 months moving averages of DMI show that the index is affected by the 6 months variability (see Figure 
22). Thus, in this paper the abnormal year of IOD is considered only for the year of 2007.

From the all 12 months averages, we observed that there is no longer than 12 months variability, or more precisely, the cyclic variability of longer than 12 months in the Indonesian Seas.

\subsection{The Seasonal Variability}

The 6 months moving averages of SST, U-WS and RR identify the signal of seasonal variability. In the High latitude region, all areas show a strong seasonal variability of all indices except for the U-WS in area B. In the Equatorial region, areas D, E and F (the inner Indonesian Seas) shows a strong seasonal variability of all indices except for the SST in area D. The other areas in the Equatorial region show a weak seasonal variability of all indices. It is noted that the ENSO Index area, area J, has no seasonal variability of all indices.

Table 2. Seasonal variability of indices

\begin{tabular}{cccc}
\hline Location & SST & UWS & RR \\
\hline Area A & Strong & Strong & Strong \\
Area B & Strong & Weak & Strong \\
Area C & Weak & Strong & Weak \\
Area D & Weak & Strong & Strong \\
Area E & Strong & Strong & Strong \\
Area F & Strong & Strong & Strong \\
Area G & Weak & Weak & Weak \\
Area H & Weak & Weak & Weak \\
Area I & Weak & Weak & Weak \\
Area J & Zero & Zero & Zero \\
Area K & Strong & Strong & Strong \\
Area L & Strong & Strong & Strong \\
\hline
\end{tabular}

Table 3. Six months variability of indices

\begin{tabular}{cccc}
\hline Location & SST & UWS & RR \\
\hline Area A & Zero & Zero & Very weak \\
Area B & Zero & Very weak & Very weak \\
Area C & Very weak & Zero & Very weak \\
Area D & Weak & Zero & Zero \\
Area E & Weak & Zero & Zero \\
Area F & Very weak & Zero & Zero \\
Area G & Very weak & Zero & Very weak \\
Area H & Weak & Very weak & Very weak \\
Area I & Very weak & Very weak & Very weak \\
Area J & Zero & Zero & Zero \\
Area K & Zero & Zero & Very weak \\
Area L & Zero & Zero & Very weak \\
\hline
\end{tabular}




\subsection{The 6 Months Variability}

The 3 months moving averages of SST, U-WS and RR identify the signal of the 6 months variability. In the High latitude region, all areas have no 6 months variability of SST and U-WS, except for the area B. The area B shows a very weak 6 months variability of U-WS. All areas in the High latitude region show a very weak 6 months variability of RR.

In the Equatorial region, areas D, E and $\mathrm{H}$ show a weak 6 months variability of SST. The other areas in the Equatorial region only show a very weak 6 months variability of SST. The areas H and I show a very weak 6 months variability of U-WS. The other areas in the Equatorial region have no 6 months variability of U-WS. The inner Indonesian Seas, areas D, E and F have no 6 months variability of RR, while the other areas in the Equator show a very weak 6 months variability of RR. It is noted that the ENSO Index area, area J, has no 6 months variability of all indices.

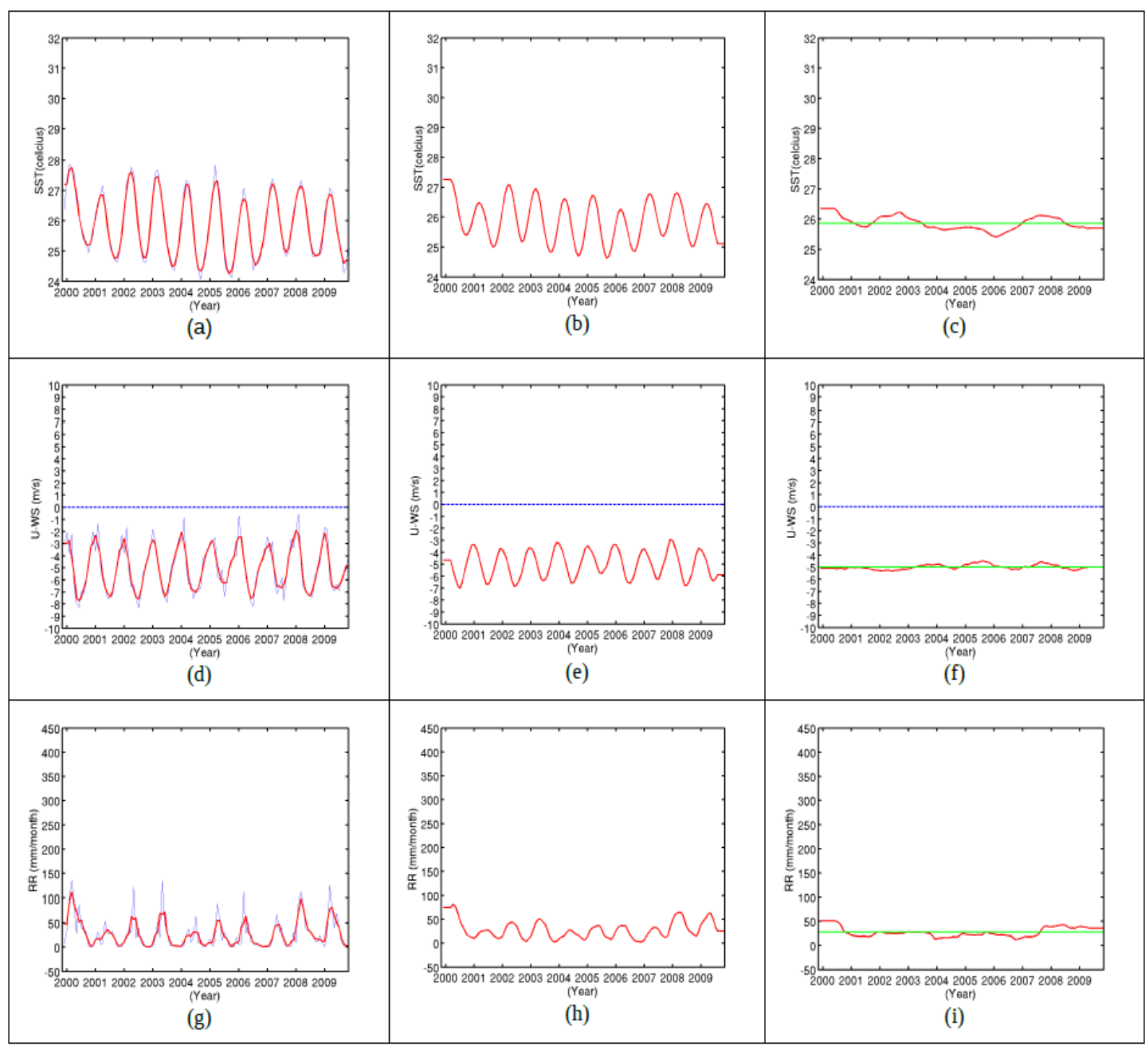

Figure 2. Moving averages of SST (upper panel), U-WS (middle panel) and RR (lower panel) in area A

The 3 months moving averages are shown in panel (a), (d) and (g); the 6 months moving averages are shown in panel (b), (e) and (h); the 12 months moving averages are shown in panel (c), (f) and (i). The red line indicates the moving averages result, the blue line indicates the original dataset and the green line indicates the average values. Axes indicate averages of indices and year. The positive values of U-WS indicate eastward direction and vice versa. 


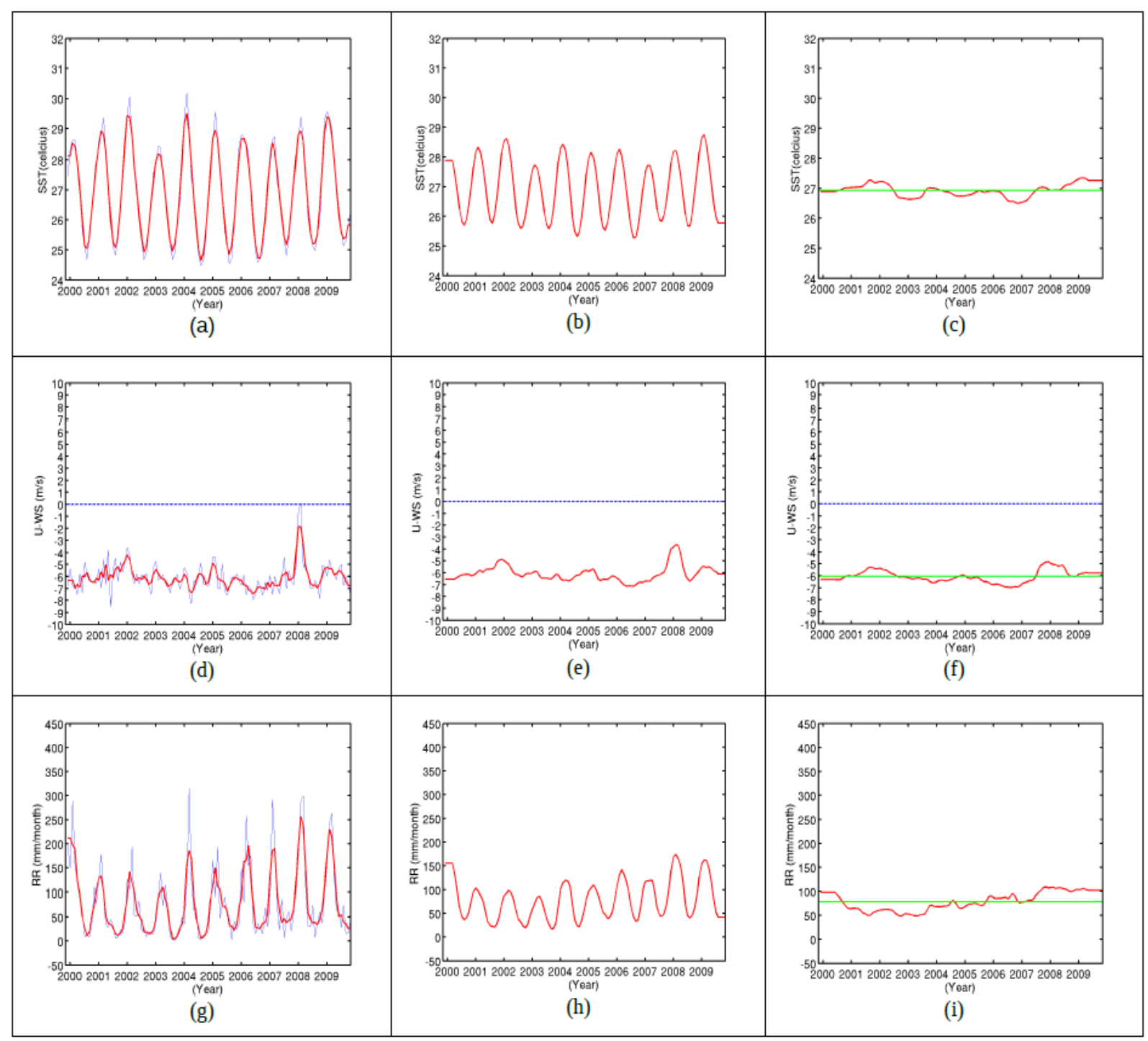

Figure 3. Moving averages of SST (upper panel), U-WS (middle panel) and RR (lower panel) in area B

The 3 months moving averages are shown in panel (a), (d) and (g); the 6 months moving averages are shown in panel (b), (e) and (h); the 12 months moving averages are shown in panel (c), (f) and (i). The red line indicates the moving averages result, the blue line indicates the original dataset and the green line indicates the average values. Axes indicate averages of indices and year. The positive values of U-WS indicate eastward direction and vice versa. 


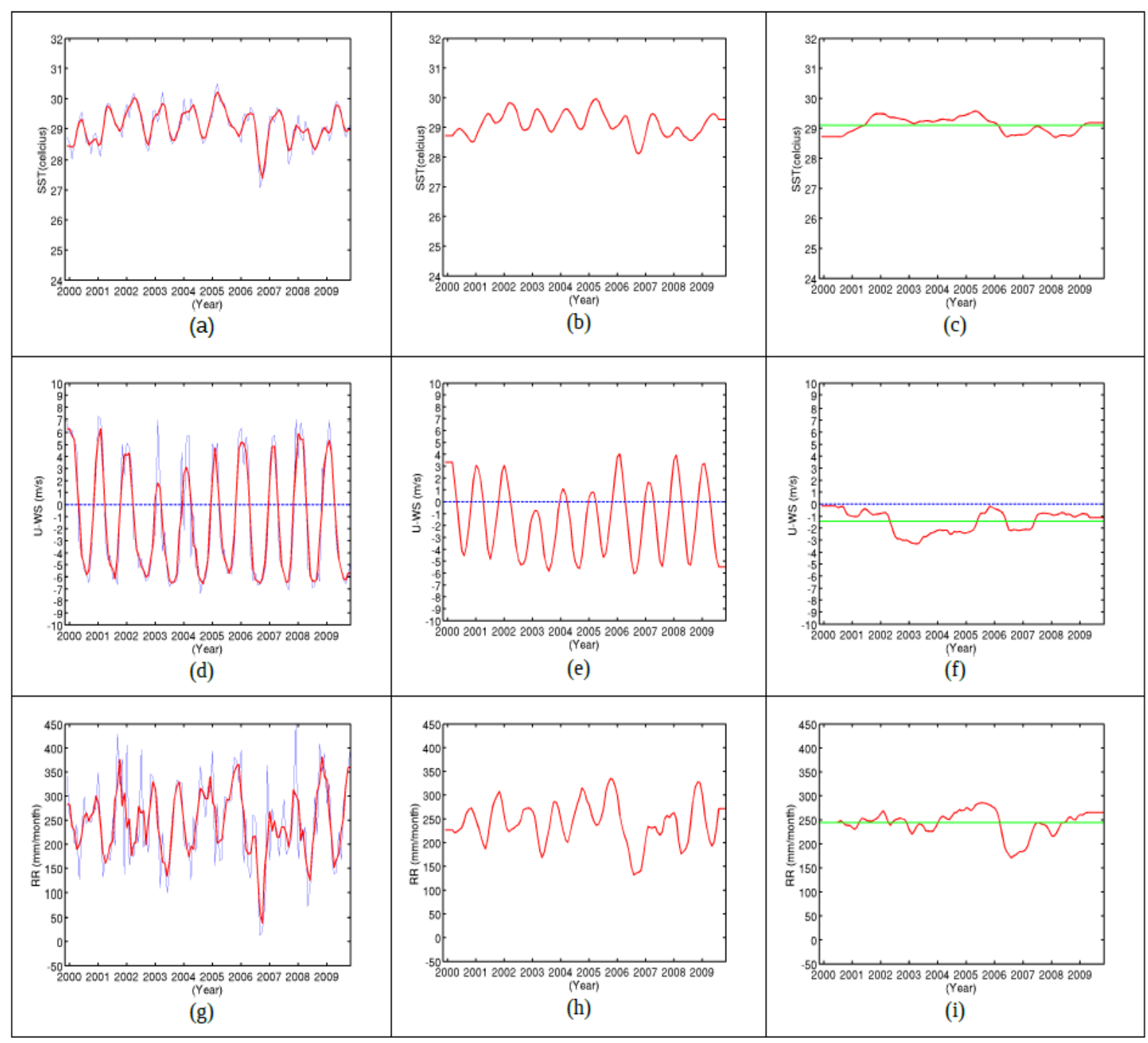

Figure 4. Moving averages of SST (upper panel), U-WS (middle panel) and RR (lower panel) in area C

The 3 months moving averages are shown in panel (a), (d) and (g); the 6 months moving averages are shown in panel (b), (e) and (h); the 12 months moving averages are shown in panel (c), (f) and (i). The red line indicates the moving averages result, the blue line indicates the original dataset and the green line indicates the average values. Axes indicate averages of indices and year. The positive values of U-WS indicate eastward direction and vice versa. 


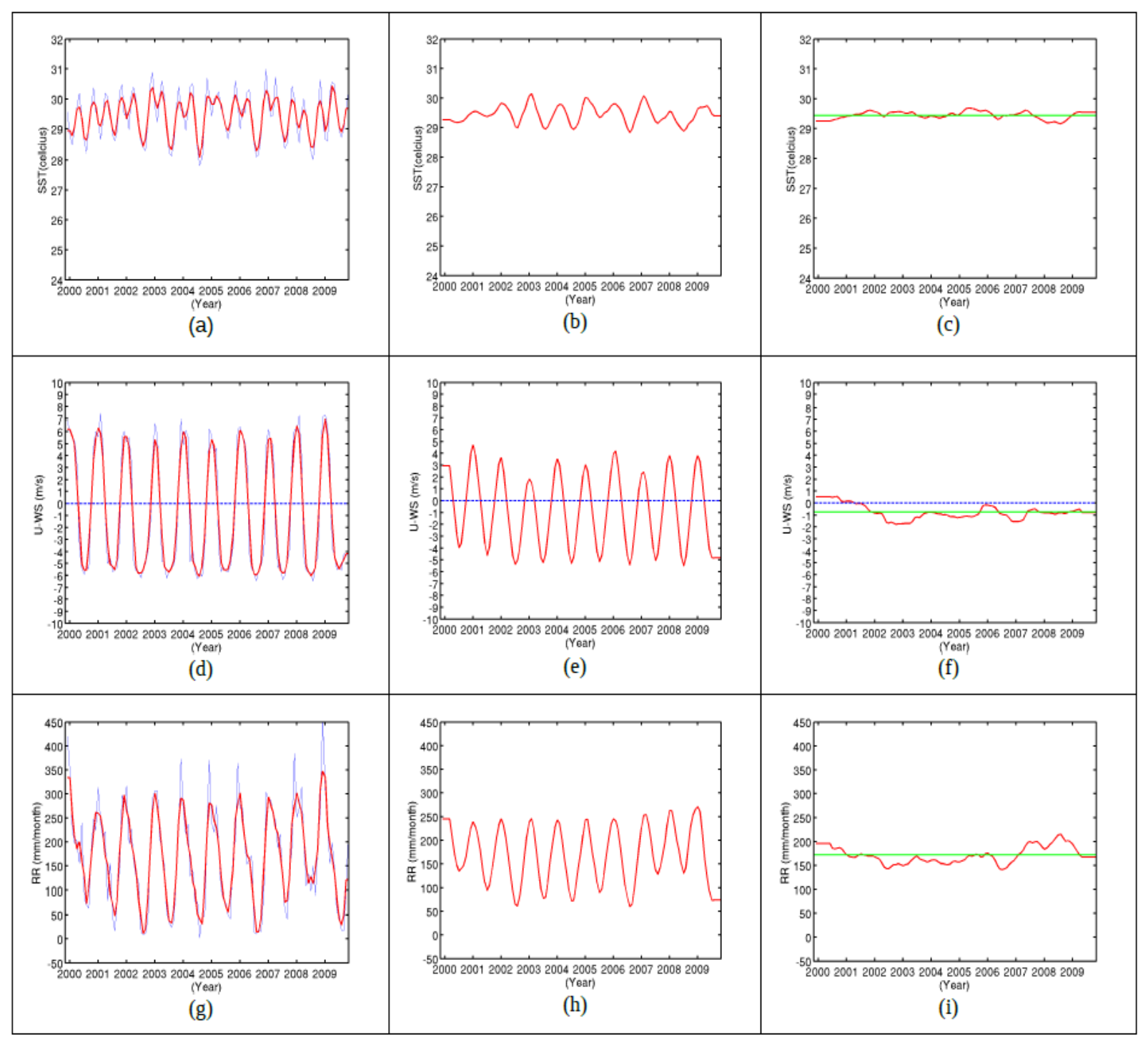

Figure 5. Moving averages of SST (upper panel), U-WS (middle panel) and RR (lower panel) in area D

The 3 months moving averages are shown in panel (a), (d) and (g); the 6 months moving averages are shown in panel (b), (e) and (h); the 12 months moving averages are shown in panel (c), (f) and (i). The red line indicates the moving averages result, the blue line indicates the original dataset and the green line indicates the average values. Axes indicate averages of indices and year. The positive values of U-WS indicate eastward direction and vice versa. 


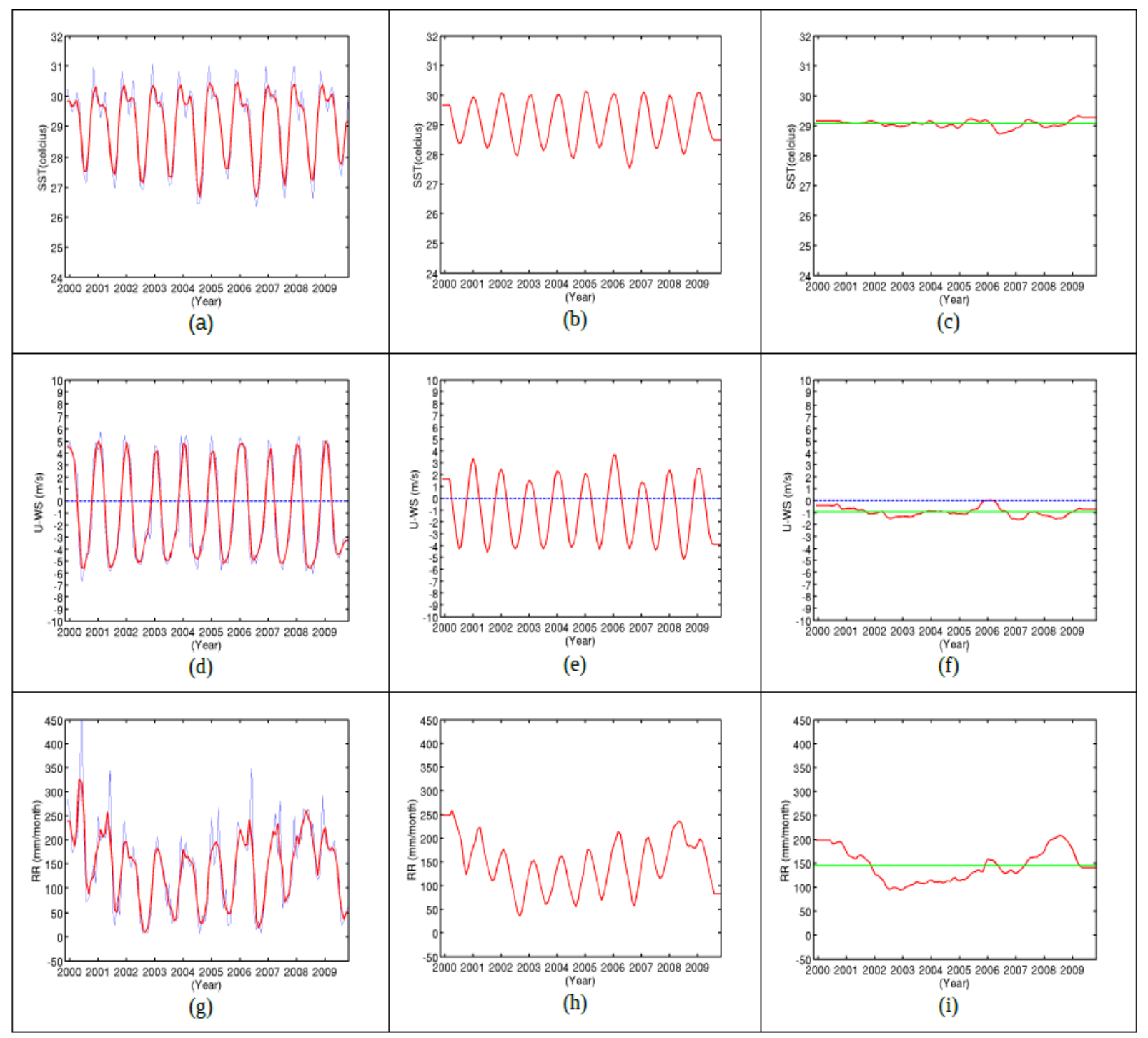

Figure 6. Moving averages of SST (upper panel), U-WS (middle panel) and RR (lower panel) in area E

The 3 months moving averages are shown in panel (a), (d) and (g); the 6 months moving averages are shown in panel (b), (e) and (h); the 12 months moving averages are shown in panel (c), (f) and (i). The red line indicates the moving averages result, the blue line indicates the original dataset and the green line indicates the average values. Axes indicate averages of indices and year. The positive values of U-WS indicate eastward direction and vice versa. 


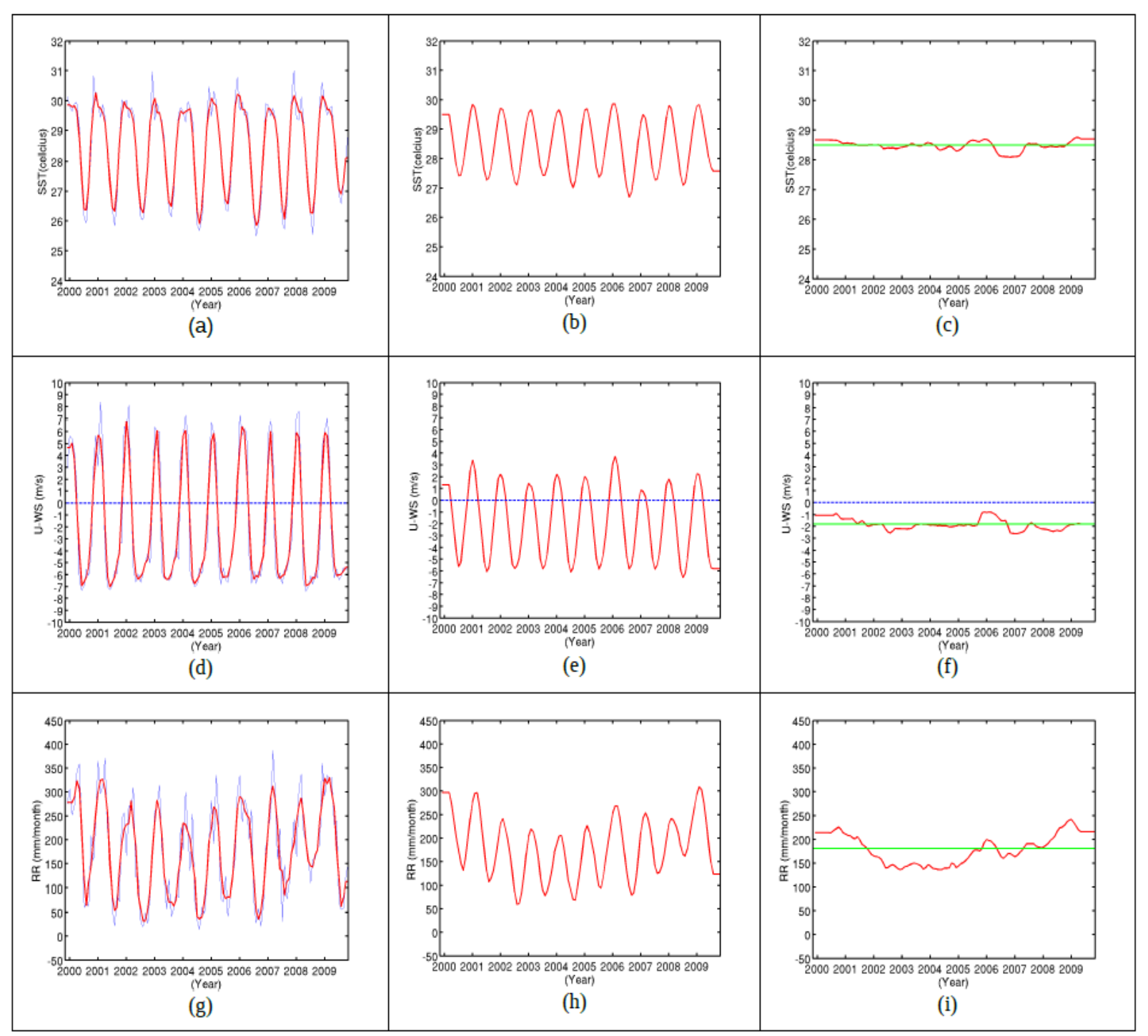

Figure 7. Moving averages of SST (upper panel), U-WS (middle panel) and RR (lower panel) in area F

The 3 months moving averages are shown in panel (a), (d) and (g); the 6 months moving averages are shown in panel (b), (e) and (h); the 12 months moving averages are shown in panel (c), (f) and (i). The red line indicates the moving averages result, the blue line indicates the original dataset and the green line indicates the average values. Axes indicate averages of indices and year. The positive values of U-WS indicate eastward direction and vice versa. 


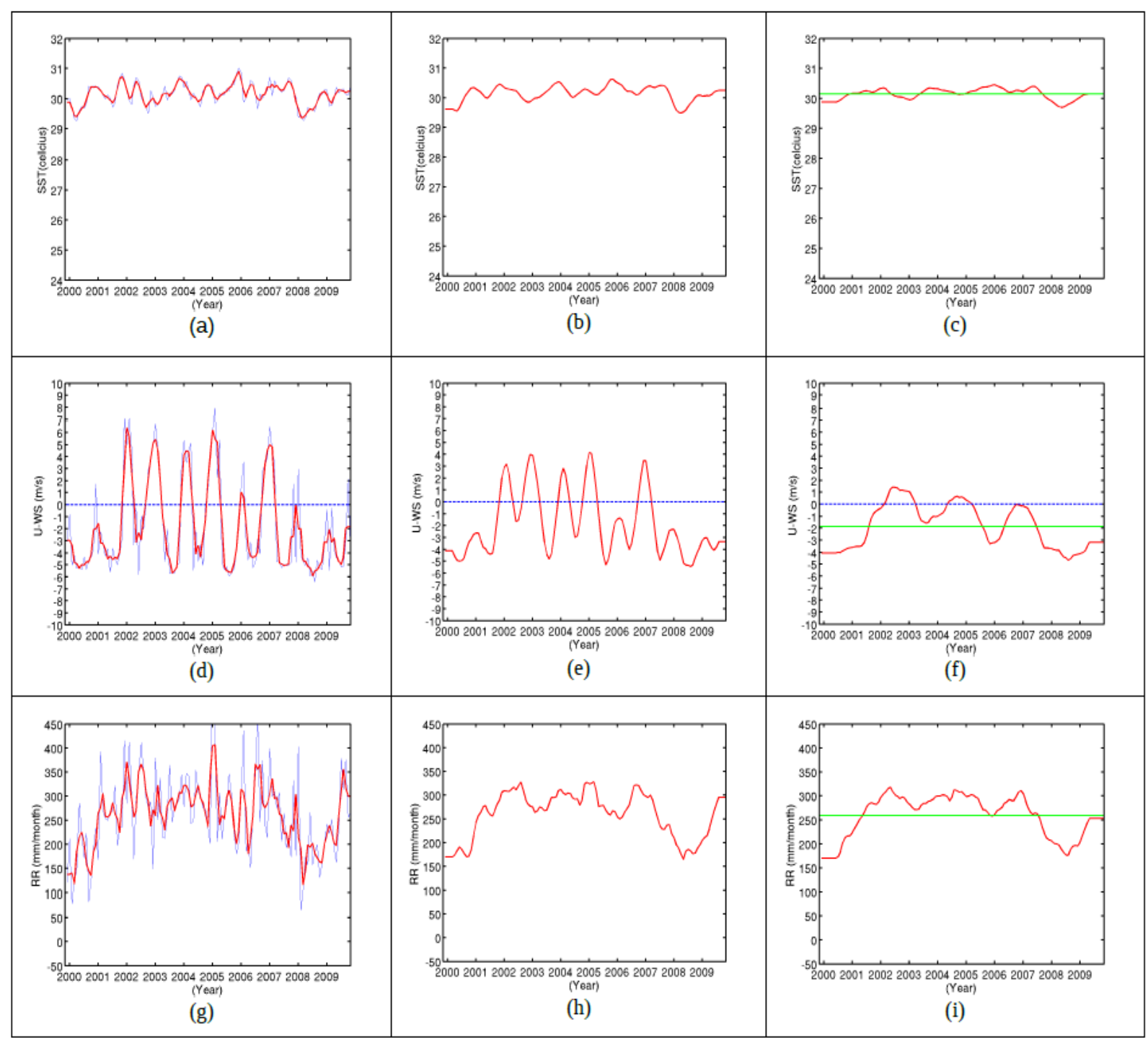

Figure 8. Moving averages of SST (upper panel), U-WS (middle panel) and RR (lower panel) in area G

The 3 months moving averages are shown in panel (a), (d) and (g); the 6 months moving averages are shown in panel (b), (e) and (h); the 12 months moving averages are shown in panel (c), (f) and (i). The red line indicates the moving averages result, the blue line indicates the original dataset and the green line indicates the average values. Axes indicate averages of indices and year. The positive values of U-WS indicate eastward direction and vice versa. 


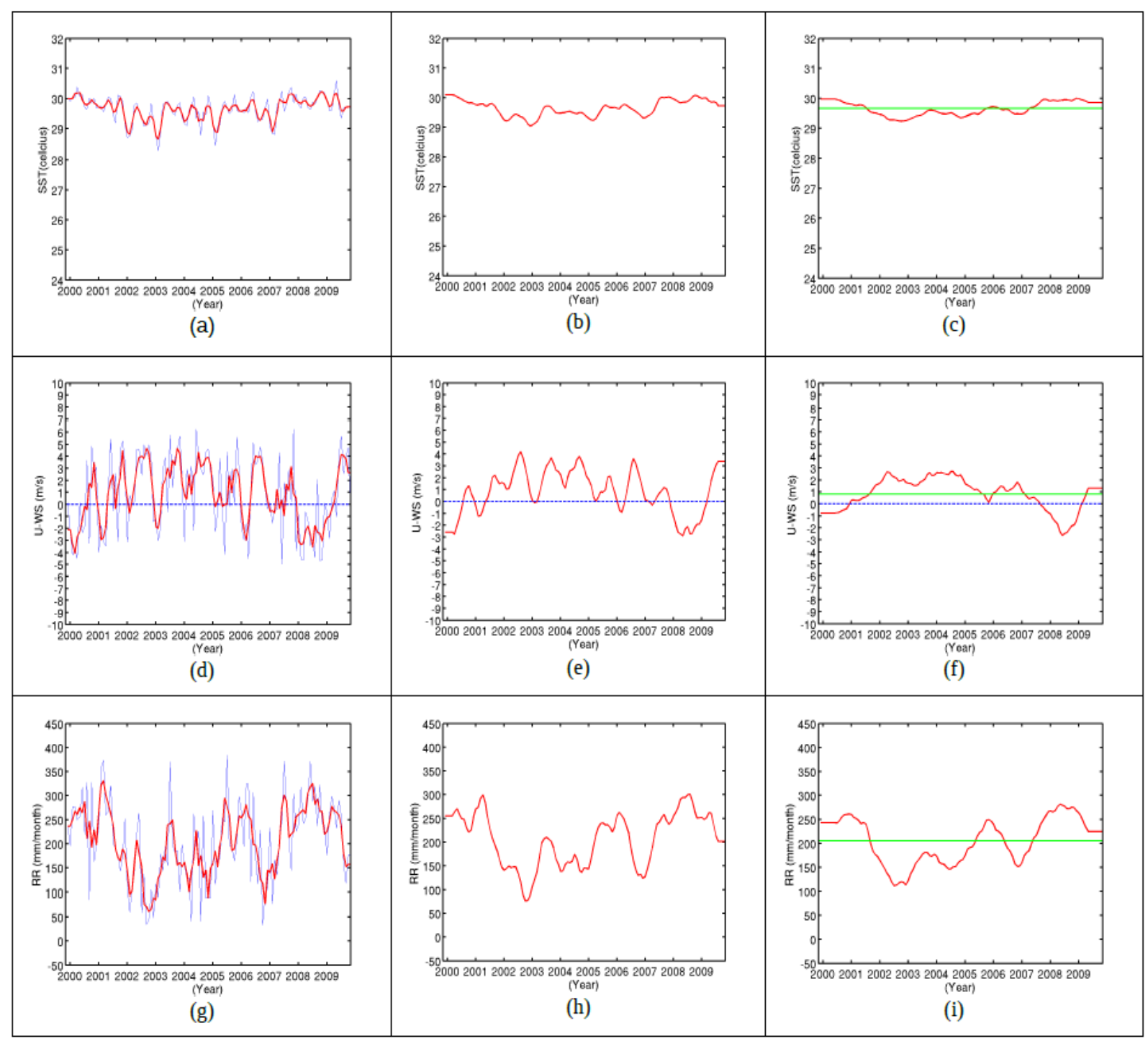

Figure 9. Moving averages of SST (upper panel), U-WS (middle panel) and RR (lower panel) in area $\mathrm{H}$

The 3 months moving averages are shown in panel (a), (d) and (g); the 6 months moving averages are shown in panel (b), (e) and (h); the 12 months moving averages are shown in panel (c), (f) and (i). The red line indicates the moving averages result, the blue line indicates the original dataset and the green line indicates the average values. Axes indicate averages of indices and year. The positive values of U-WS indicate eastward direction and vice versa. 


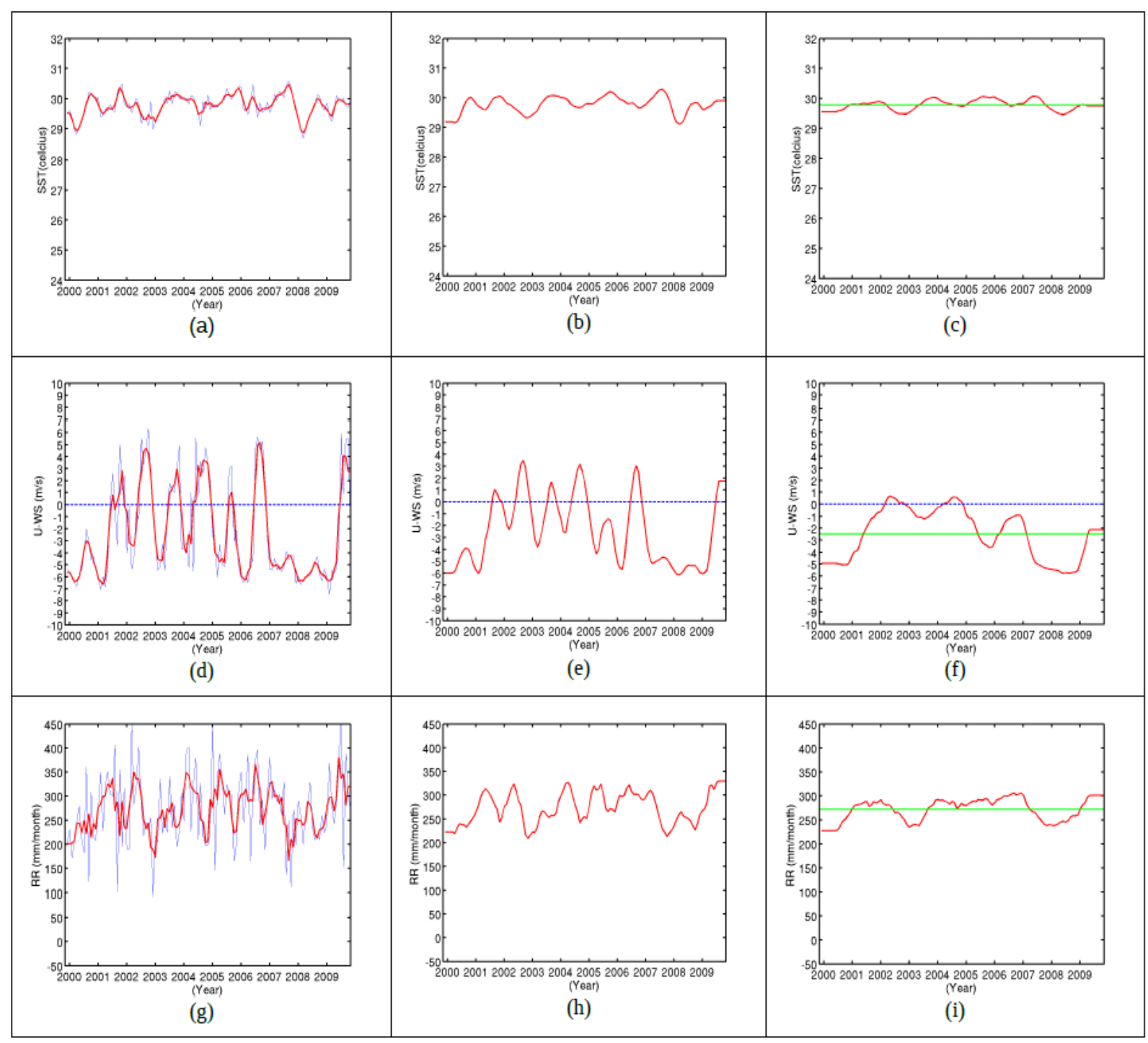

Figure 10. Moving averages of SST (upper panel), U-WS (middle panel) and RR (lower panel) in area I

The 3 months moving averages are shown in panel (a), (d) and (g); the 6 months moving averages are shown in panel (b), (e) and (h); the 12 months moving averages are shown in panel (c), (f) and (i). The red line indicates the moving averages result, the blue line indicates the original dataset and the green line indicates the average values. Axes indicate averages of indices and year. The positive values of U-WS indicate eastward direction and vice versa. 


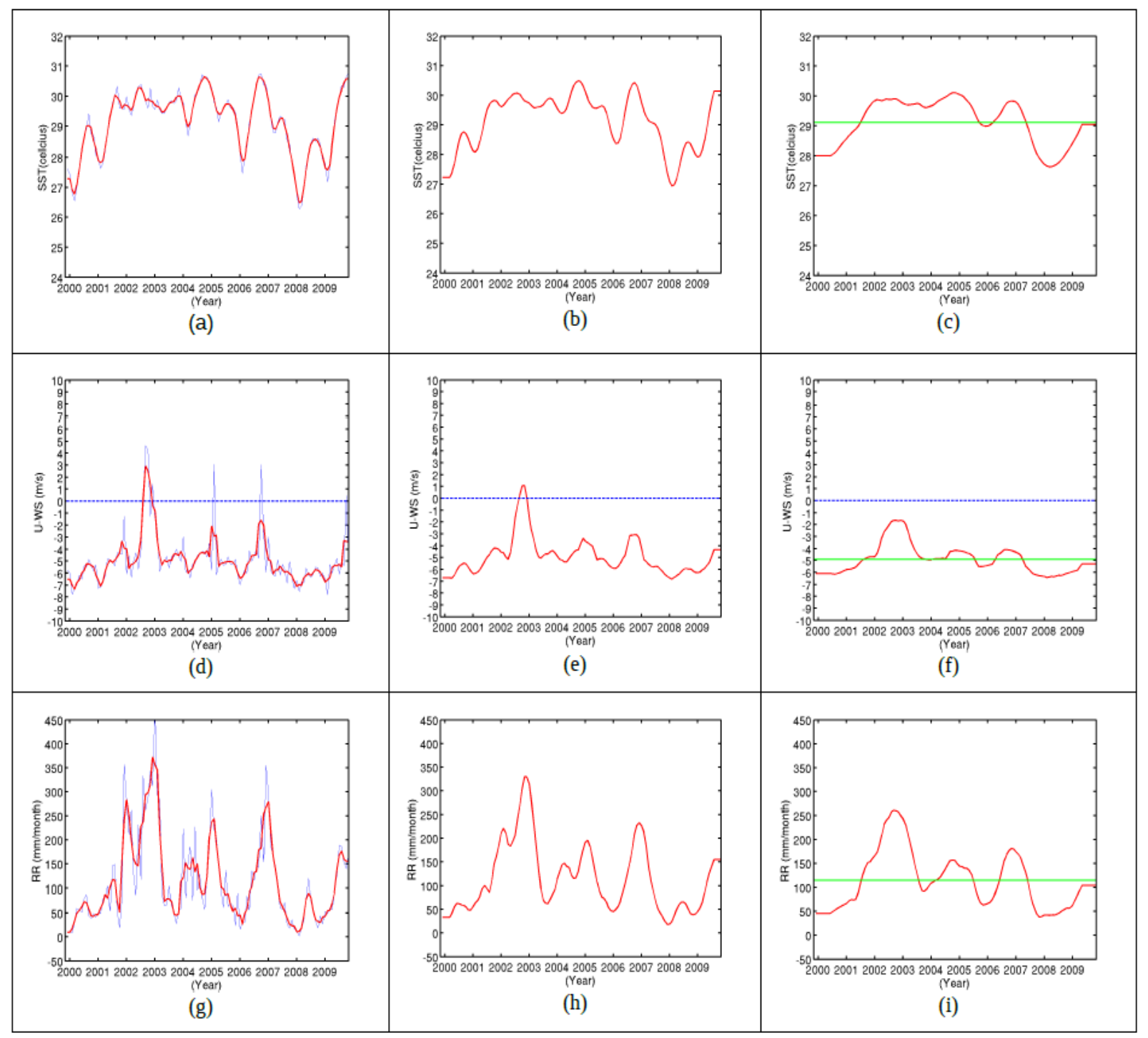

Figure 11. Moving averages of SST (upper panel), U-WS (middle panel) and RR (lower panel) in area J

The 3 months moving averages are shown in panel (a), (d) and (g); the 6 months moving averages are shown in panel (b), (e) and (h); the 12 months moving averages are shown in panel (c), (f) and (i). The red line indicates the moving averages result, the blue line indicates the original dataset and the green line indicates the average values. Axes indicate averages of indices and year. The positive values of U-WS indicate eastward direction and vice versa. 


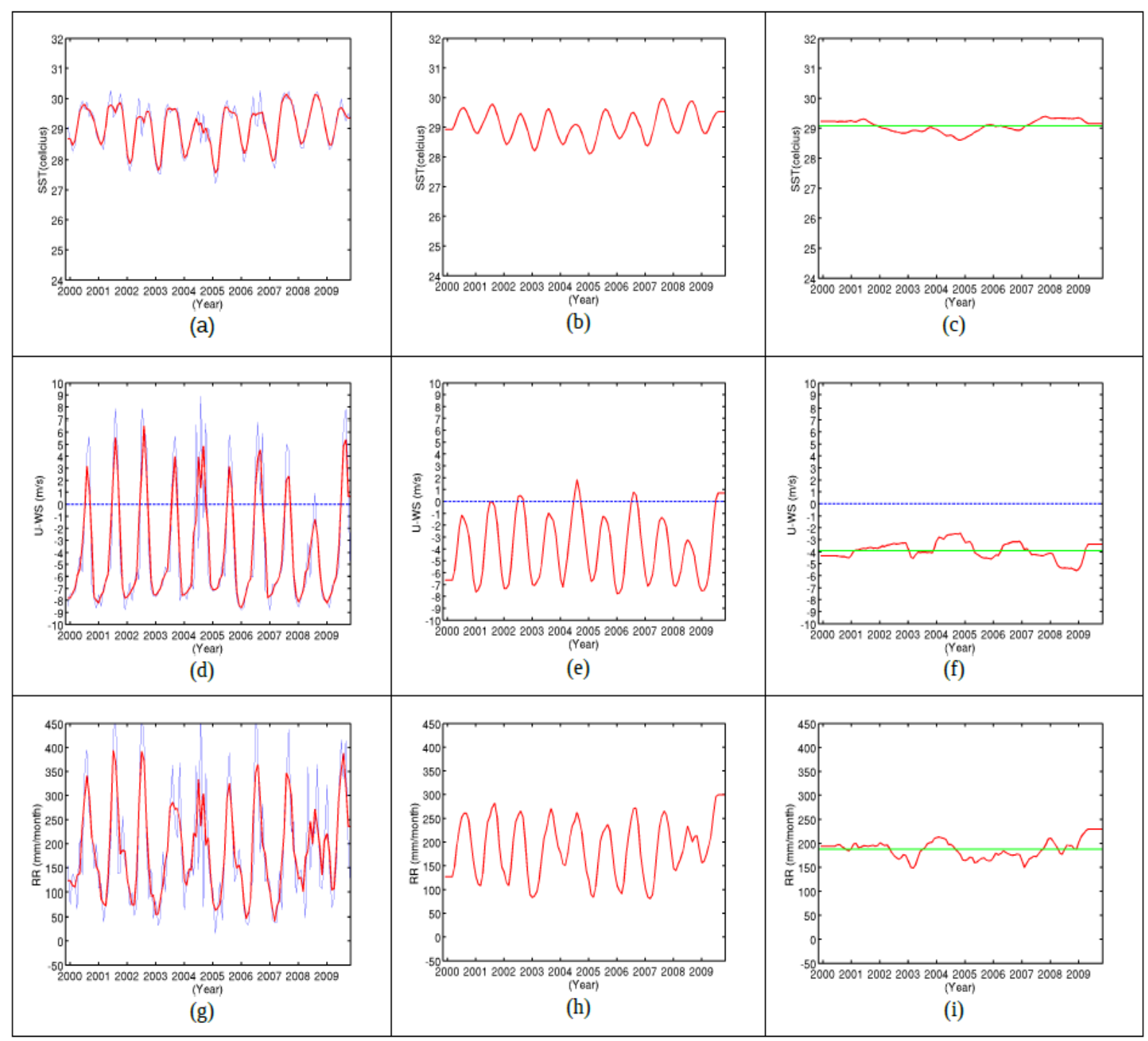

Figure 12. Moving averages of SST (upper panel), U-WS (middle panel) and RR (lower panel) in area K

The 3 months moving averages are shown in panel (a), (d) and (g); the 6 months moving averages are shown in panel (b), (e) and (h); the 12 months moving averages are shown in panel (c), (f) and (i). The red line indicates the moving averages result, the blue line indicates the original dataset and the green line indicates the average values. Axes indicate averages of indices and year. The positive values of U-WS indicate eastward direction and vice versa. 


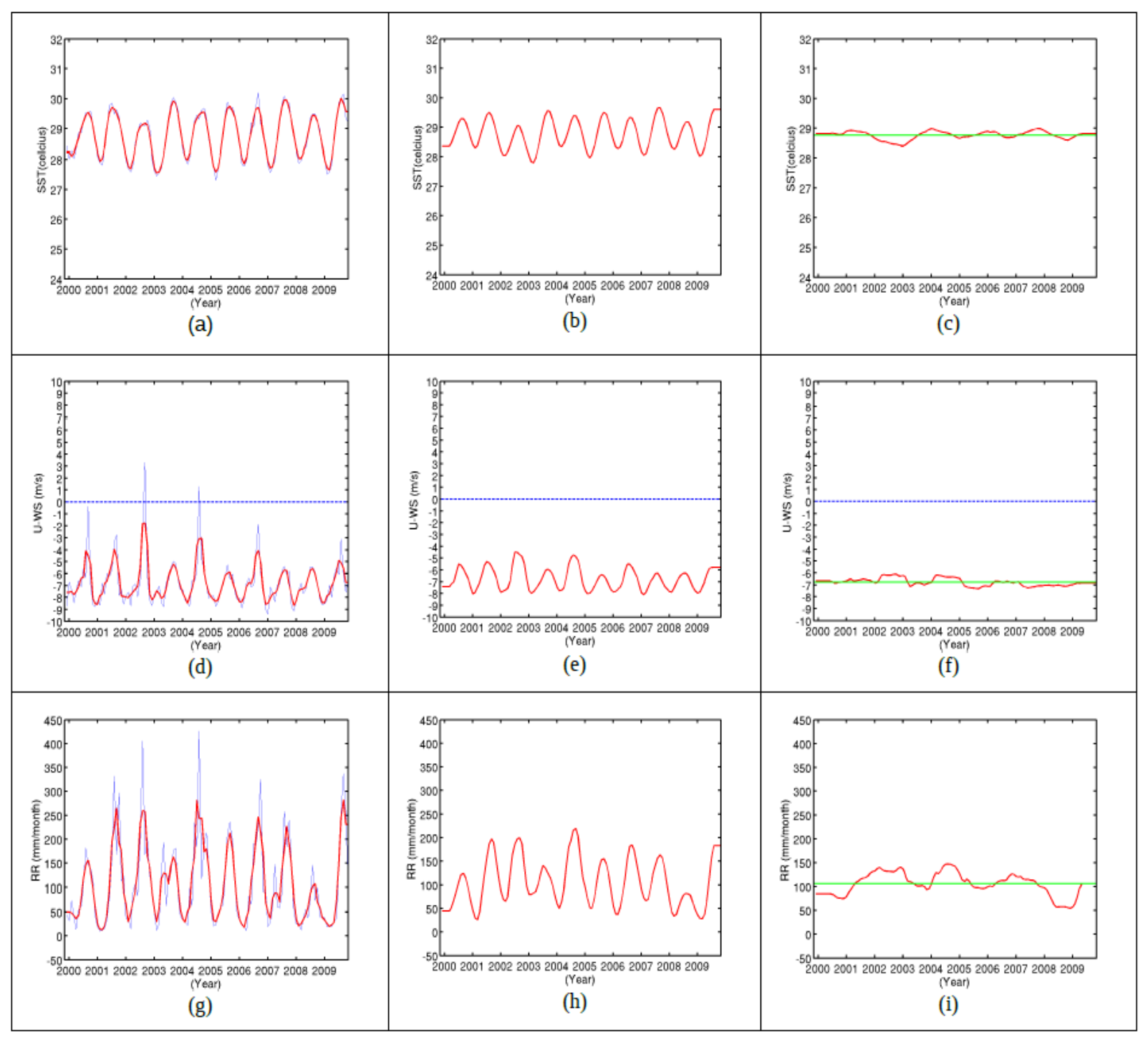

Figure 13. Moving averages result of SST (upper panel), U-WS (middle panel) and RR (lower panel) in area L

The 3 months moving averages are shown in panel (a), (d) and (g); the 6 months moving averages are shown in panel (b), (e) and (h); the 12 months moving averages are shown in panel (c), (f) and (i). The red line indicates the moving averages result, the blue line indicates the original dataset and the green line indicates the average values. Axes indicate averages of indices and year. The positive values of U-WS indicate eastward direction and vice versa

\subsection{The Auto-Correlation and Cross-Correlation Analyses}

We further calculate the auto-correlation of SST, U-WS and RR to find out the temporal variability of indices for those areas with a weak seasonal variability: the areas G, H, I and J in the Equatorial Pacific Ocean (see Figures 14 to 16). These areas have no clear temporal variability of SST and RR, except for areas H. The area H shows combined seasonal and 6 months variability of SST. The temporal variability of U-WS in all areas shows the seasonal variability, except for the ENSO Index area, area $\mathrm{J}$.

We also calculate the cross-correlation among the indices. In the High latitude region, all areas show a strong correlation among indices, except for the area B. The lag time of SST and U-WS for area A is -2 months (it means that the SST comes 2 months later after the U-WS), while those for areas K and L are -1 month. The lag times of U-WS and RR for the areas A, K and L are -2, 0 and 1 months, respectively. The lag times of SST and $\mathrm{RR}$ for the areas $\mathrm{A}, \mathrm{K}$ and $\mathrm{L}$ are 2, 1 and 0 months, respectively. The area $\mathrm{B}$ only shows a strong correlation between SST and RR with 1 month lag time. 
In the Equatorial region, areas D, E and F (the inner Indonesian Seas) show a strong correlation among indices. The lag time of SST and U-WS for area D is 5 months, while those for areas E and F are 0 month. The lag times of U-WS and RR for areas D, E and F are 0, 2 and 1 months, respectively. The lag time of SST and RR for area $\mathrm{D}$ is 0 month, while those for areas $\mathrm{E}$ and $\mathrm{F}$ are 1 month. The area $\mathrm{C}$ only shows a strong correlation between SST and U-WS with 4 months lag times. The ENSO Index area, area J, has no lag time among indices.

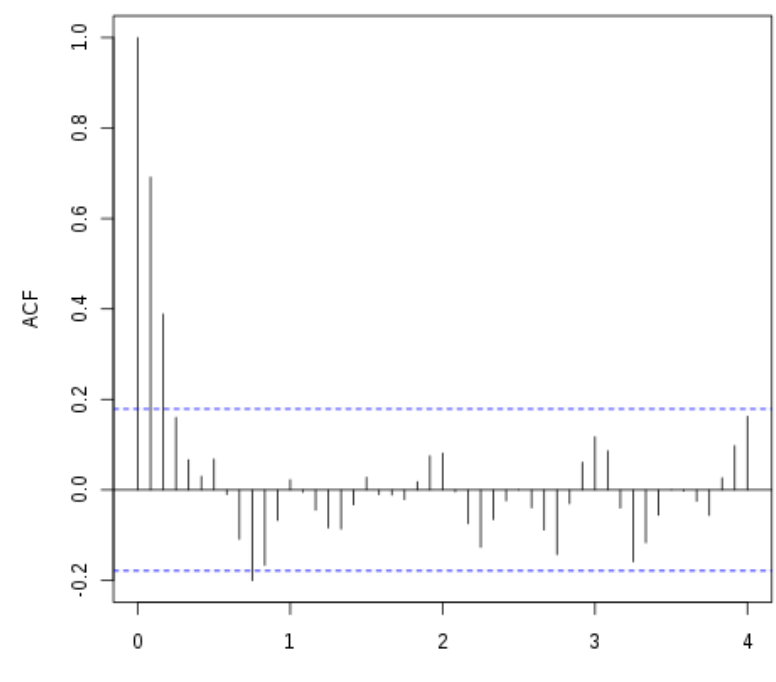

(a)

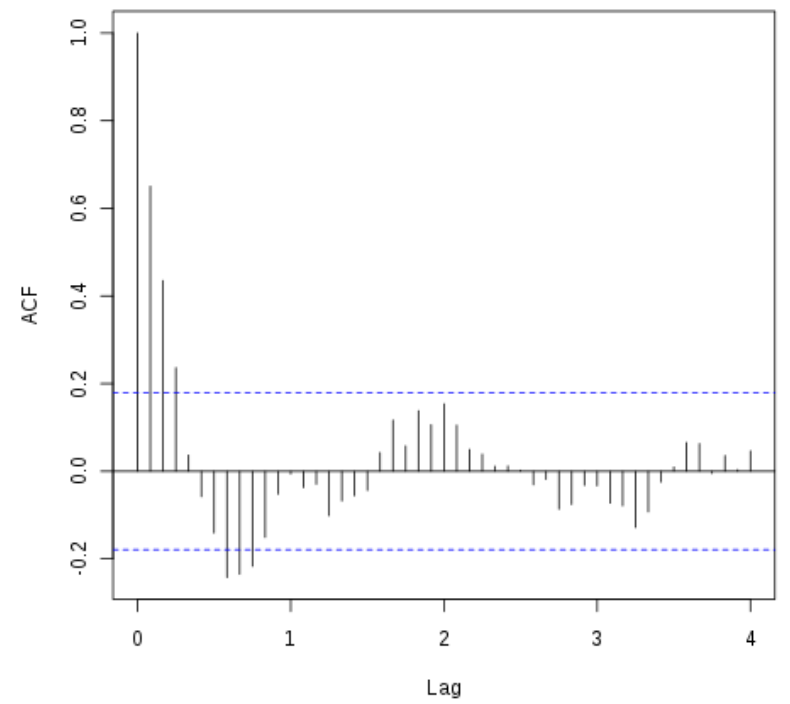

(c)

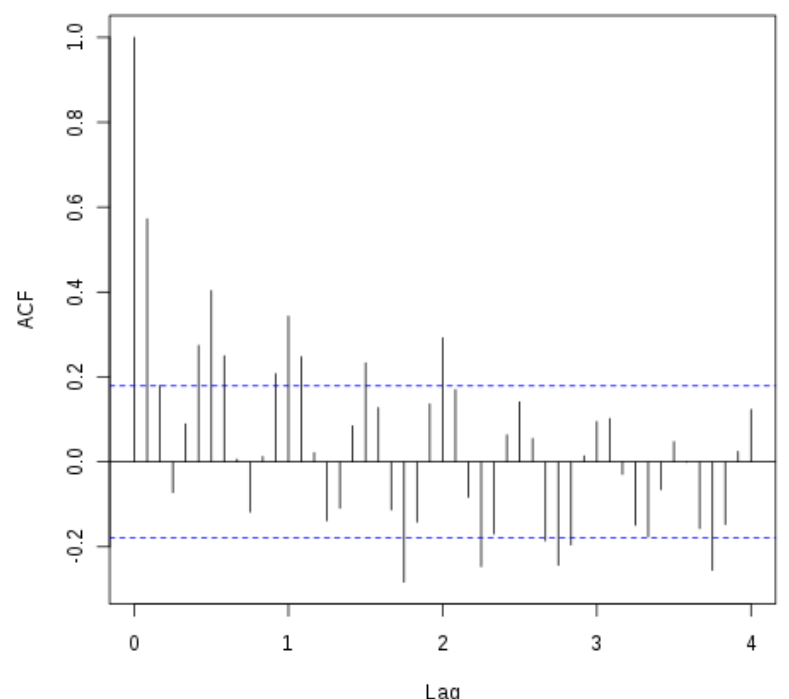

(b)

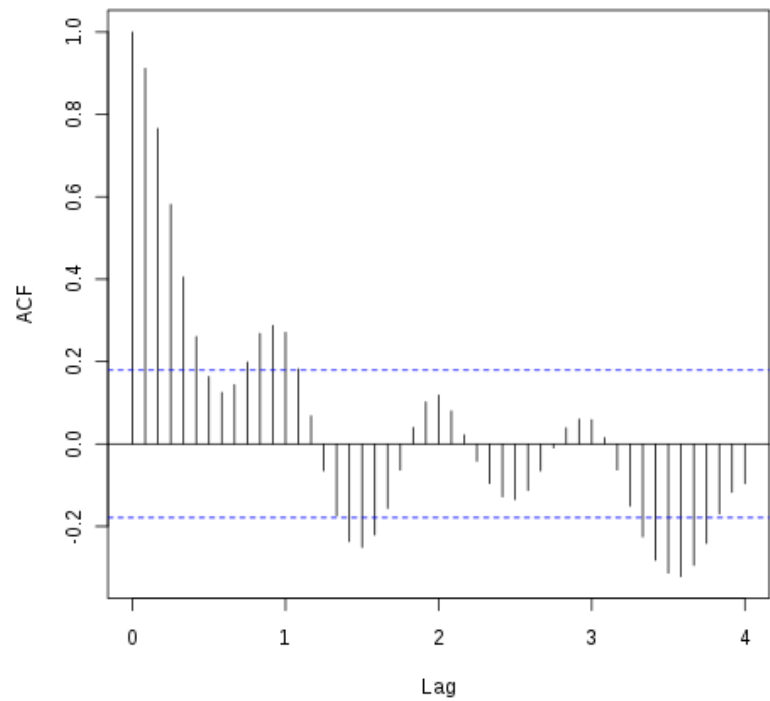

(d)

Figure 14. The auto-correlation of SST within 4 years in area G (panel a), area H (panel b), area I (panel c) and area $\mathrm{J}$ (panel d)

Axes indicate the correlation values and time lag. 


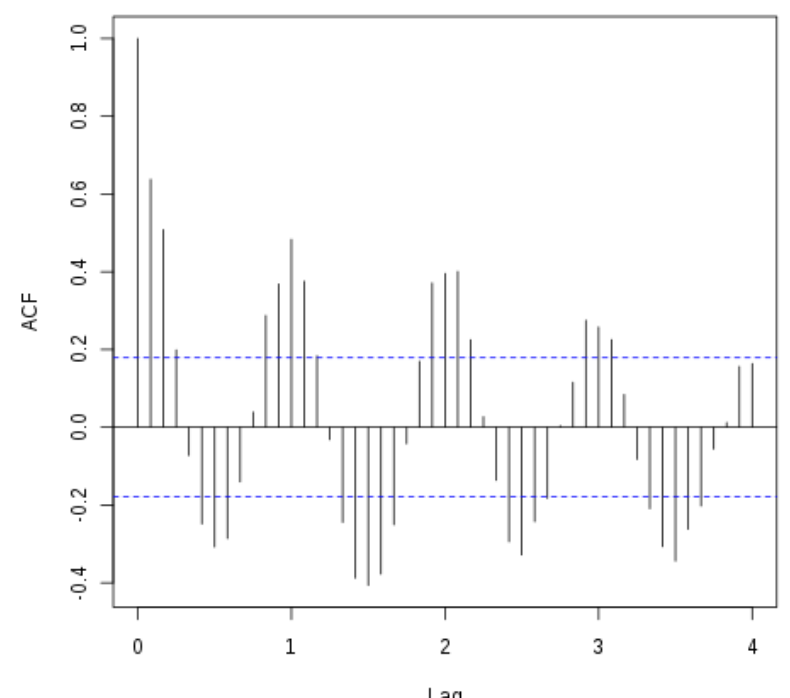

(a)

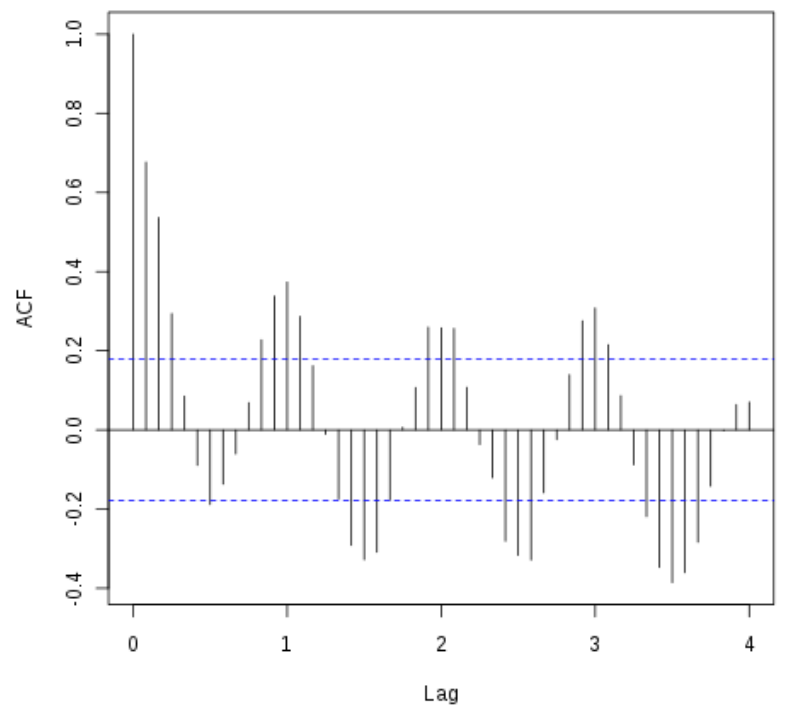

(c)

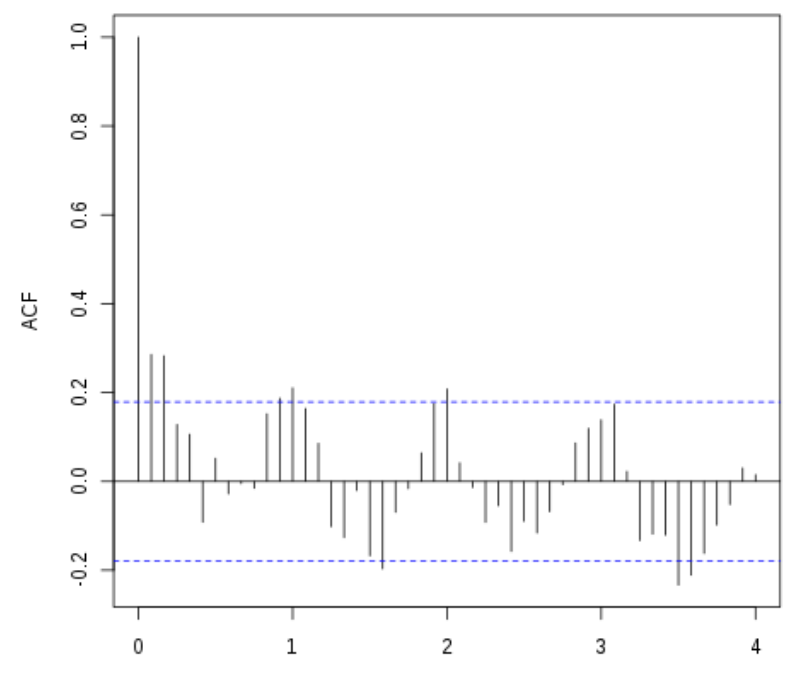

(b)

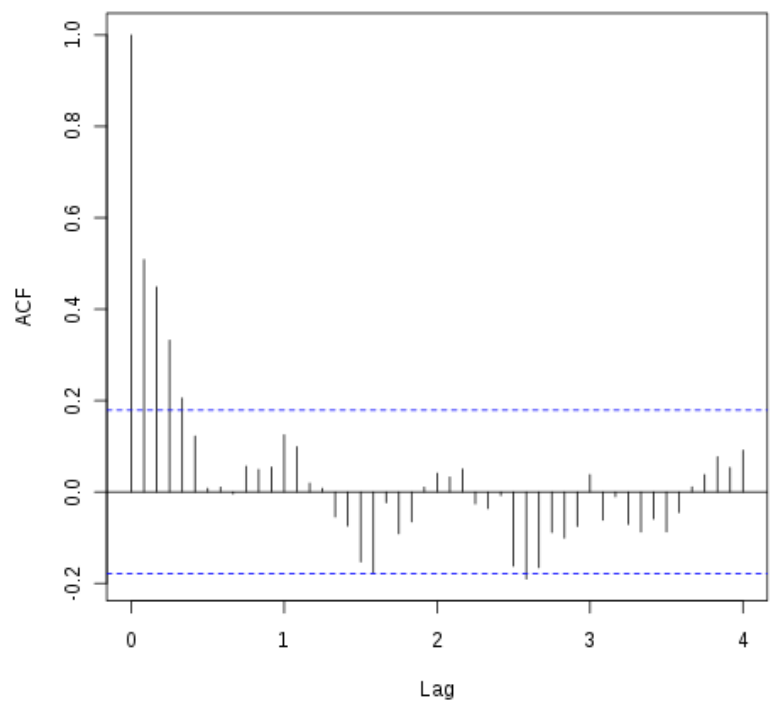

(d)

Figure 15. The auto-correlation of U-WS within 4 years in area G (panel a), area H (panel b), area I (panel c) and area $\mathbf{J}$ (panel d)

Axes indicate the correlation values and time lag.

Table 4. Auto-correlation of indices

\begin{tabular}{lccc}
\hline \multirow{2}{*}{ Location } & \multicolumn{3}{c}{ Variability } \\
\cline { 2 - 4 } & SST & UWS & RR \\
\hline Area G & NC & 1 Year & NC \\
Area H & 6 months & 1 Year & NC \\
Area I & NC & 1 Year & NC \\
Area J & NC & NC & NC \\
\hline
\end{tabular}

The NC symbol indicates the variability is not clear. 


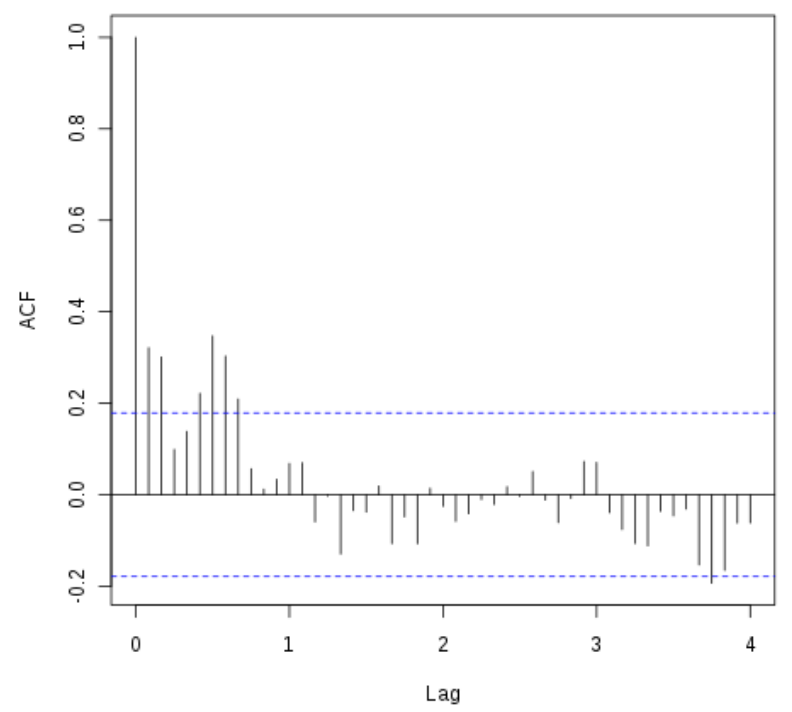

(a)

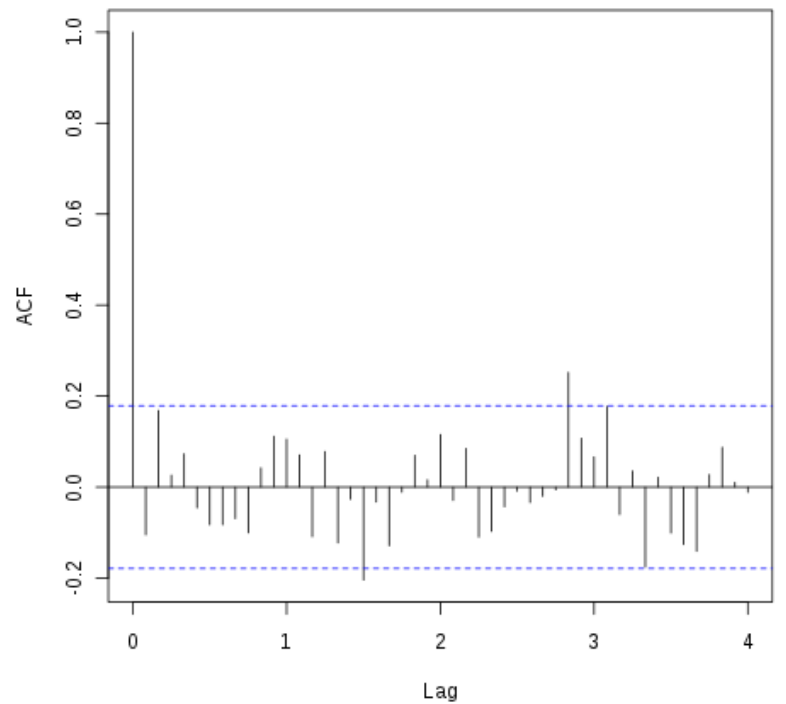

(c)

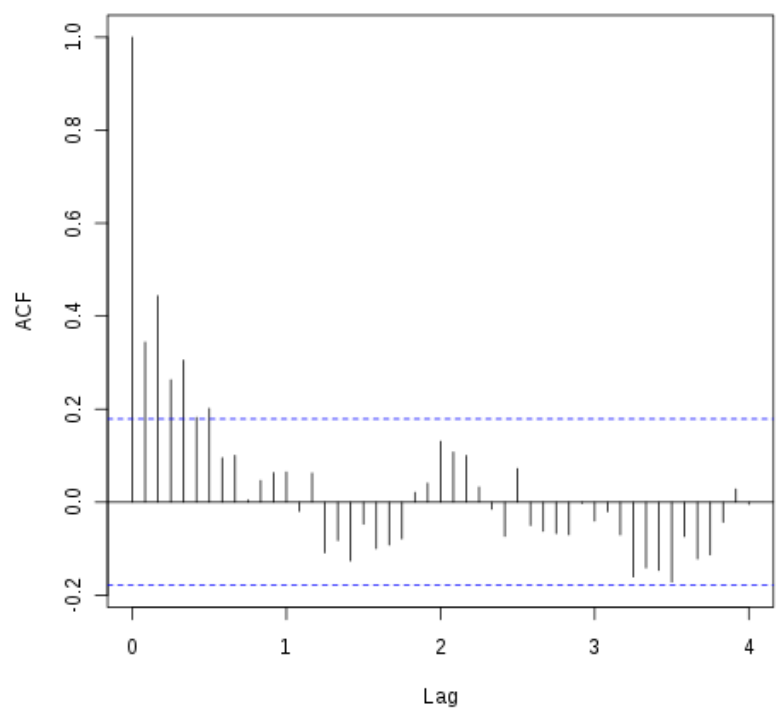

(b)

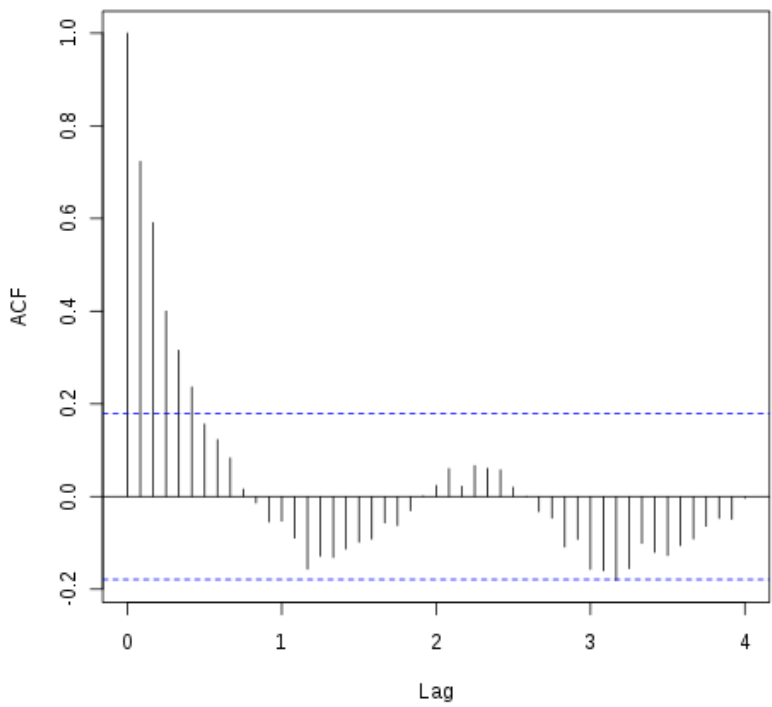

(d)

Figure 16. The auto-correlation of RR within 4 years in area G (panel a), area H (panel b), area I (panel c) and area $\mathrm{J}$ (panel d)

Axes indicate the correlation values and time lag.

\subsection{The Connection of Indices with ENSO and IOD}

The ENSO and IOD indices are defined as SST. We first consider the connection of SST in the Indonesian Seas with the ENSO and IOD signals (see Figures 17 to 20). Based on the comparison, we can discern the effect of the ENSO and IOD signals on the local areas.

In the Pacific Ocean, the areas H and I (the Equatorial region) show both El Nino and La Nina signals of SST. The area G (the Equatorial region) shows La Nina signal but no El Nino signal of SST. The area K (the High latitude region) shows both El Nino and La Nina signals of SST. The area B (the High latitude region) shows El Nino signal but no La Nina signal, while area L (the High latitude region) has no El Nino and no La Nina signals of SST.

In the inner Indonesian Seas, areas D, E and F, has no El Nino and no La Nina signals of SST, except for the areas $\mathrm{E}$ and $\mathrm{F}$ in the year of 2007. The abnormal signal of areas $\mathrm{E}$ and $\mathrm{F}$ in 2007 might be caused by IOD. This fact implies that the variability of SST in the areas E and F in 2007 might be caused and enhanced by the combined El Nino and IOD. The combined enhancement of La Nina and IOD might give a significant impact, but this enhancement has not occurred in our study period. 
In the Indian Ocean, the area A (the High latitude region) has no El Nino and no La Nina signals of SST. The area $\mathrm{C}$ (the Equatorial region) shows the El Nino and La Nina signals of SST.

For the response of U-WS and RR, the area A (the High latitude Indian Ocean) only shows the El Nino and La Nina signals of RR. The area C (the Equatorial Indian Ocean) only shows the El Nino and La Nina signals of U-WS. All areas in the High latitude Pacific Ocean show the El Nino and La Nina signals of U-WS and RR, except for the area B. The area B (the High latitude Pacific Ocean) has no El Nino and no La Nina signals of U-WS. All areas in the Equatorial Pacific Ocean and the inner Indonesian Seas show the El Nino and La Nina signals of U-WS and RR.

Table 5. Time-lagged correlation among indices

\begin{tabular}{|c|c|c|c|c|c|c|}
\hline \multirow{2}{*}{ Location } & \multicolumn{2}{|c|}{ SST - UWS } & \multicolumn{2}{|c|}{ UWS - RR } & \multicolumn{2}{|c|}{ SST - RR } \\
\hline & Cor. & Lag (month) & Cor. & Lag (month) & Cor. & Lag (month) \\
\hline Area A & 0.80 & -2 & 0.60 & -2 & 0.71 & 2 \\
\hline Area B & Very low & - & Very low & - & 0.76 & 1 \\
\hline Area C & -0.53 & 4 & Very low & - & Very low & - \\
\hline Area D & -0.55 & 5 & 0.68 & 0 & 0.60 & 0 \\
\hline Area E & 0.66 & 0 & 0.59 & 2 & 0.74 & 1 \\
\hline Area F & 0.69 & 0 & 0.65 & 1 & 0.78 & 1 \\
\hline Area G & Very low & - & Very low & - & Very low & - \\
\hline Area H & Very low & - & Very low & - & Very low & - \\
\hline Area I & Very low & - & Very low & - & Very low & - \\
\hline Area $\mathrm{J}$ & 0.52 & 0 & 0.50 & 0 & 0.68 & 0 \\
\hline Area K & 0.50 & -1 & 0.64 & 0 & 0.68 & 1 \\
\hline Area L & 0.61 & -1 & 0.56 & 1 & 0.76 & 0 \\
\hline
\end{tabular}

Table 6. El Nino signal from the 6 months moving averages of the deseasonalized dataset

\begin{tabular}{|c|c|c|c|c|c|c|c|c|c|}
\hline \multirow{2}{*}{ Location } & \multicolumn{3}{|c|}{ SST } & \multicolumn{3}{|c|}{ UWS } & \multicolumn{3}{|c|}{$\mathrm{RR}$} \\
\hline & $02 / 03$ & $04 / 05$ & 06/07 & $02 / 03$ & $04 / 05$ & $06 / 07$ & $02 / 03$ & $04 / 05$ & $06 / 07$ \\
\hline Area A & $\mathrm{NC}$ & $\mathrm{NC}$ & $\mathrm{NC}$ & $\mathrm{NC}$ & $\mathrm{NC}$ & $\mathrm{NC}$ & $\mathrm{NC}$ & $\mathrm{D}$ & $\mathrm{D}$ \\
\hline Area B & $\mathrm{D}$ & $\mathrm{D}$ & $\mathrm{D}$ & $\mathrm{NC}$ & $\mathrm{NC}$ & $\mathrm{NC}$ & $\mathrm{D}$ & $\mathrm{D}$ & $\mathrm{NC}$ \\
\hline Area $\mathrm{C}$ & $\mathrm{D}$ & $\mathrm{D}$ & $\mathrm{NC}$ & $\mathrm{D}$ & $\mathrm{D}$ & $\mathrm{D}$ & $\mathrm{NC}$ & $\mathrm{NC}$ & $\mathrm{NC}$ \\
\hline Area D & $\mathrm{NC}$ & $\mathrm{NC}$ & $\mathrm{NC}$ & $\mathrm{D}$ & $\mathrm{NC}$ & $\mathrm{D}$ & $\mathrm{D}$ & $\mathrm{D}$ & $\mathrm{D}$ \\
\hline Area E & $\mathrm{NC}$ & $\mathrm{NC}$ & $\mathrm{D}$ & $\mathrm{D}$ & $\mathrm{NC}$ & $\mathrm{D}$ & $\mathrm{D}$ & $\mathrm{D}$ & $\mathrm{D}$ \\
\hline Area F & $\mathrm{NC}$ & $\mathrm{NC}$ & $\mathrm{D}$ & $\mathrm{D}$ & $\mathrm{NC}$ & $\mathrm{D}$ & $\mathrm{D}$ & $\mathrm{D}$ & $\mathrm{D}$ \\
\hline Area G & $\mathrm{D}$ & $\mathrm{NC}$ & $\mathrm{NC}$ & $\mathrm{D}$ & $\mathrm{D}$ & $\mathrm{D}$ & $\mathrm{D}$ & $\mathrm{D}$ & $\mathrm{D}$ \\
\hline Area H & $\mathrm{D}$ & $\mathrm{D}$ & $\mathrm{D}$ & $\mathrm{D}$ & $\mathrm{D}$ & $\mathrm{D}$ & $\mathrm{D}$ & $\mathrm{D}$ & $\mathrm{D}$ \\
\hline Area I & $\mathrm{D}$ & $\mathrm{D}$ & $\mathrm{D}$ & $\mathrm{D}$ & $\mathrm{D}$ & $\mathrm{D}$ & $\mathrm{D}$ & $\mathrm{D}$ & $\mathrm{D}$ \\
\hline Area $\mathrm{J}$ & $\mathrm{D}$ & $\mathrm{D}$ & $\mathrm{D}$ & $\mathrm{D}$ & $\mathrm{D}$ & $\mathrm{D}$ & $\mathrm{D}$ & $\mathrm{D}$ & $\mathrm{D}$ \\
\hline Area K & $\mathrm{D}$ & $\mathrm{D}$ & $\mathrm{NC}$ & $\mathrm{D}$ & $\mathrm{D}$ & $\mathrm{D}$ & $\mathrm{D}$ & $\mathrm{D}$ & $\mathrm{NC}$ \\
\hline Area L & $\mathrm{NC}$ & $\mathrm{NC}$ & $\mathrm{NC}$ & $\mathrm{D}$ & $\mathrm{D}$ & $\mathrm{NC}$ & $\mathrm{D}$ & $\mathrm{D}$ & $\mathrm{D}$ \\
\hline
\end{tabular}

The $\mathrm{D}$ symbol indicates the signal can be detected, while NC indicates the signal is not clear. 
Table 7. La Nina signal from the 6 months moving averages of the deseasonalized dataset

\begin{tabular}{|c|c|c|c|c|c|c|c|c|c|c|c|c|}
\hline \multirow{2}{*}{ Location } & \multicolumn{4}{|c|}{ SST } & \multicolumn{4}{|c|}{ UWS } & \multicolumn{4}{|c|}{ RR } \\
\hline & $00 / 01$ & $05 / 06$ & $07 / 08$ & $08 / 09$ & $00 / 01$ & $05 / 06$ & $07 / 08$ & $08 / 09$ & $00 / 01$ & $05 / 06$ & $07 / 08$ & $08 / 09$ \\
\hline Area A & $\mathrm{NC}$ & $\mathrm{NC}$ & $\mathrm{NC}$ & $\mathrm{NC}$ & $\mathrm{NC}$ & $\mathrm{NC}$ & $\mathrm{NC}$ & $\mathrm{NC}$ & $\mathrm{D}$ & $\mathrm{NC}$ & $\mathrm{D}$ & $\mathrm{D}$ \\
\hline Area B & $\mathrm{NC}$ & $\mathrm{NC}$ & $\mathrm{NC}$ & D & $\mathrm{NC}$ & $\mathrm{NC}$ & $\mathrm{NC}$ & $\mathrm{NC}$ & D & $\mathrm{NC}$ & D & D \\
\hline Area C & D & $\mathrm{NC}$ & D & D & $\mathrm{D}$ & $\mathrm{D}$ & D & $\mathrm{D}$ & $\mathrm{NC}$ & $\mathrm{NC}$ & $\mathrm{NC}$ & $\mathrm{NC}$ \\
\hline Area D & $\mathrm{NC}$ & $\mathrm{NC}$ & $\mathrm{NC}$ & $\mathrm{NC}$ & D & D & D & D & D & $\mathrm{NC}$ & D & $\mathrm{D}$ \\
\hline Area E & $\mathrm{NC}$ & $\mathrm{NC}$ & $\mathrm{NC}$ & $\mathrm{NC}$ & D & $\mathrm{D}$ & $\mathrm{NC}$ & $\mathrm{NC}$ & D & $\mathrm{D}$ & D & $\mathrm{D}$ \\
\hline Area F & $\mathrm{NC}$ & $\mathrm{NC}$ & $\mathrm{NC}$ & $\mathrm{NC}$ & D & D & $\mathrm{NC}$ & $\mathrm{NC}$ & D & D & D & D \\
\hline Area $G$ & $\mathrm{NC}$ & $\mathrm{D}$ & $\mathrm{D}$ & $\mathrm{NC}$ & $\mathrm{D}$ & $\mathrm{D}$ & $\mathrm{D}$ & $\mathrm{D}$ & D & $\mathrm{NC}$ & $\mathrm{D}$ & $\mathrm{D}$ \\
\hline Area $\mathrm{H}$ & D & $\mathrm{NC}$ & D & D & $\mathrm{D}$ & $\mathrm{D}$ & $\mathrm{D}$ & $\mathrm{D}$ & D & $\mathrm{D}$ & $\mathrm{D}$ & $\mathrm{D}$ \\
\hline Area I & $\mathrm{NC}$ & $\mathrm{D}$ & D & $\mathrm{NC}$ & $\mathrm{D}$ & $\mathrm{D}$ & $\mathrm{D}$ & $\mathrm{D}$ & D & $\mathrm{NC}$ & D & $\mathrm{D}$ \\
\hline Area $\mathrm{J}$ & D & D & D & D & D & D & D & D & D & D & D & $\mathrm{D}$ \\
\hline Area K & D & $\mathrm{NC}$ & D & D & D & D & D & D & $\mathrm{NC}$ & D & D & $\mathrm{D}$ \\
\hline Area L & $\mathrm{NC}$ & $\mathrm{NC}$ & $\mathrm{NC}$ & $\mathrm{NC}$ & $\mathrm{NC}$ & $\mathrm{D}$ & D & D & D & D & D & D \\
\hline
\end{tabular}

The $\mathrm{D}$ symbol indicates the signal can be detected, while $\mathrm{NC}$ indicates the signal is not clear.

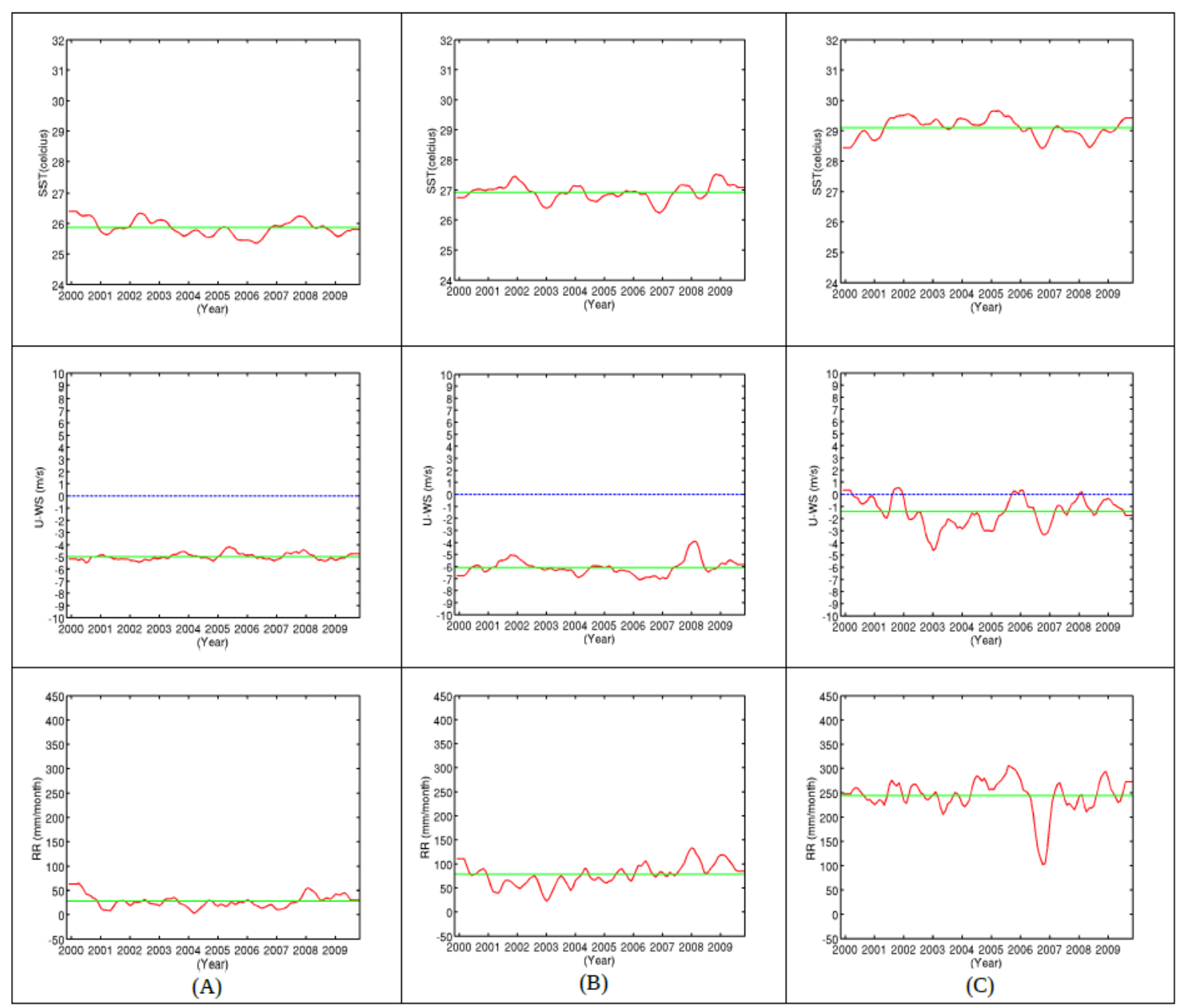

Figure 17. The 6 months moving averages of the deseasonalized dataset in area A (left panel), area B (middle panel) and area $\mathrm{C}$ (right panel)

The upper panel shows the SST; the middle panel shows the U-WS; and the lower panel shows the RR. The red line indicates the moving averages result and the green line indicates the average values. 


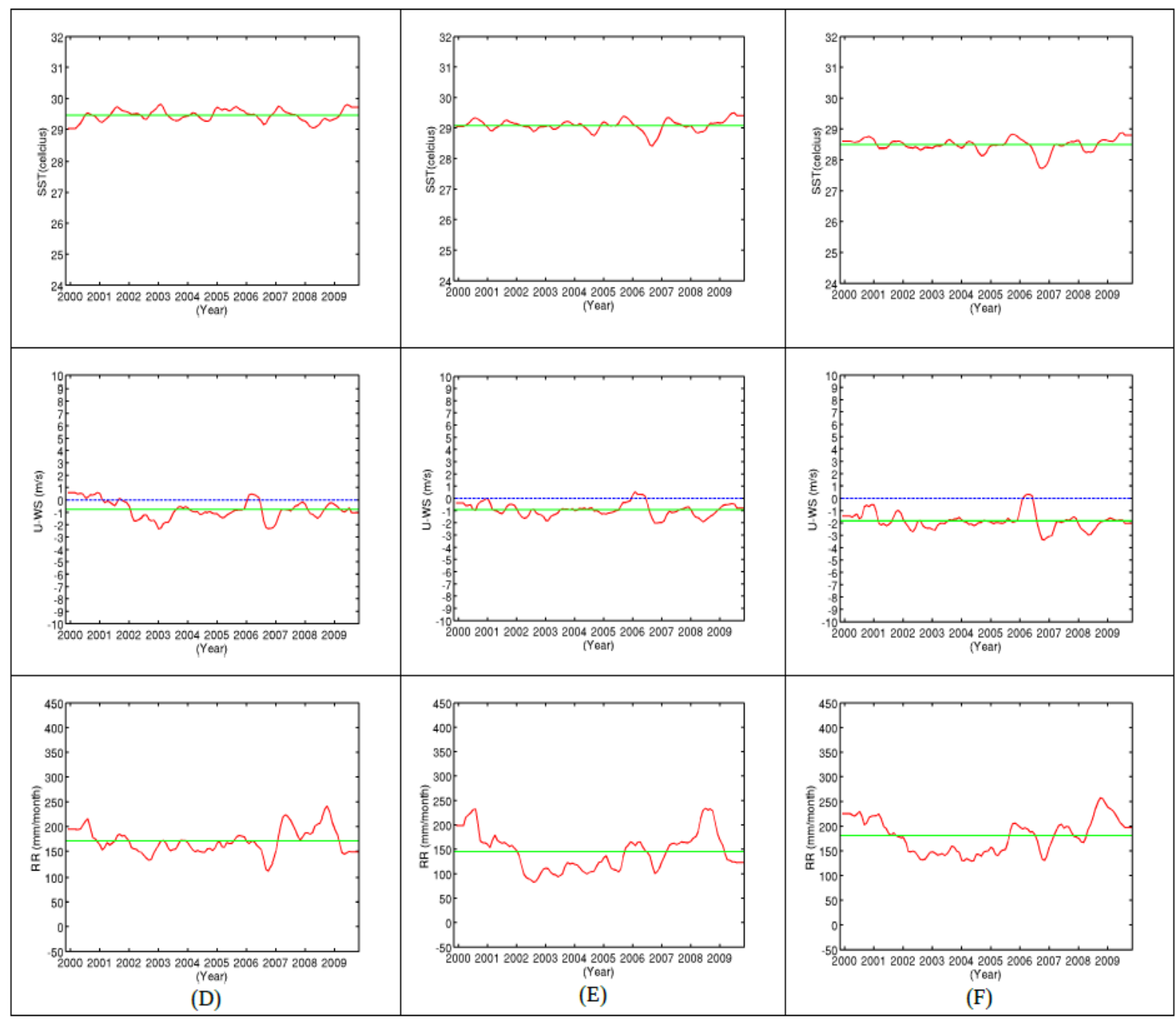

Figure 18. The 6 months moving averages of the deseasonalized dataset in area D (left panel), area $\mathrm{E}$ (middle panel) and area $\mathrm{F}$ (right panel)

The upper panel shows the SST; the middle panel shows the U-WS; and the lower panel shows the RR. The red line indicates the moving averages result and the green line indicates the average values. 


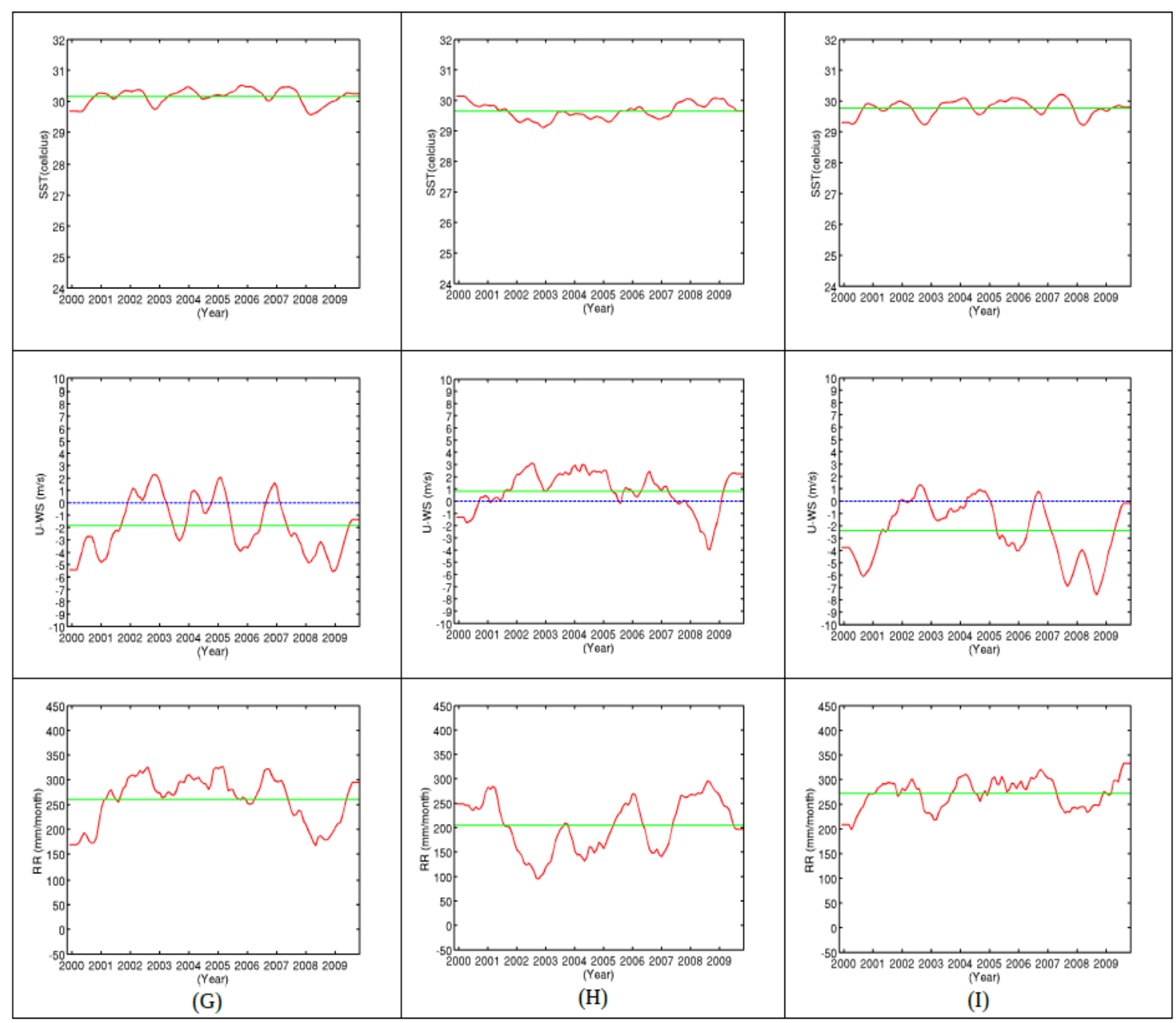

Figure 19. The 6 months moving averages of the deseasonalized dataset in area $\mathrm{G}$ (left panel), area H (middle panel) and area I (right panel)

The upper panel shows the SST; the middle panel shows the U-WS; and the lower panel shows the RR. The red line indicates the moving averages result and the green line indicates the average values. 


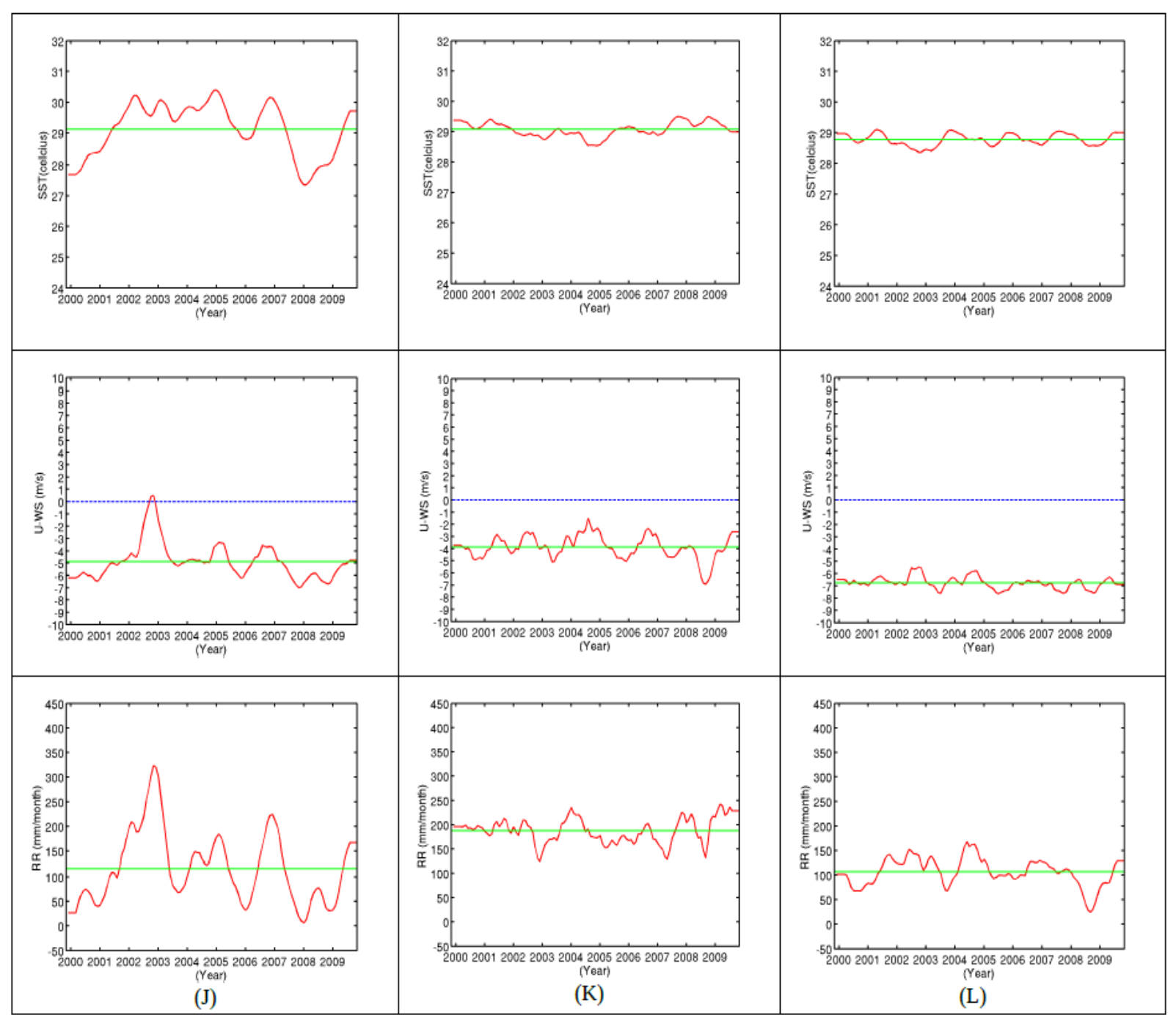

Figure 20. The 6 months moving averages of the deseasonalized dataset in area $\mathrm{J}$ (left panel), area K (middle panel) and area $\mathrm{L}$ (right panel)

The upper panel shows the SST; the middle panel shows the U-WS; and the lower panel shows the RR. The red line indicates the moving averages result and the green line indicates the average values.

\subsection{The Local Characteristics}

The inner Indonesian Seas, areas D, E and F, show the seasonal variability of all indices. However, the area D has more stable SST than the area E, while both areas have a similar U-WS pattern (see Figures 5 and 6). The difference of SST between areas D and E might be caused by the ocean bathymetry (see Figure 1).

The U-WS in the inner Indonesian Seas switches from west to east and vice versa, while it does not change its direction in the outside areas of the inner Indonesian Seas (see Figures 5 to 7). This is the monsoon wind pattern of the inner Indonesian Seas. Saveral studies have described the monsoon pattern of the inner Indonesian Seas (Wyrtki, 1962; Susanto et al., 2006), but the pattern was unclear (Swardika et al., 2012).

\section{Conclusions}

The local characteristics of SST, U-WS and RR in the Indonesian Seas are analysed using satellite remote sensing datasets from December 1999 - November 2009. The seasonal variability of the indices is strong in the High latitude region and the inner Indonesian Seas. The 6 months variability of SST is weakly detected in the several areas of the Equatorial region. The inner Indonesian Seas has a strong correlation among indices, but the lag times among indices vary and we can not find out any discernment regarding them. The ENSO signal of SST can be detected in the High latitude Pacific Ocean and the Equatorial region, except for the inner Indonesian 
Seas. The inner Indonesian Sea only shows the ENSO signal of SST in the year 2007, but it, rather, might be caused by the positive IOD. We show the variabilities and connections of the 12 areas to the ENSO and IOD, but it is difficult to obtain any finding that fits all the areas. One typical locality is the SST difference between the areas $\mathrm{D}$ and $\mathrm{E}$.

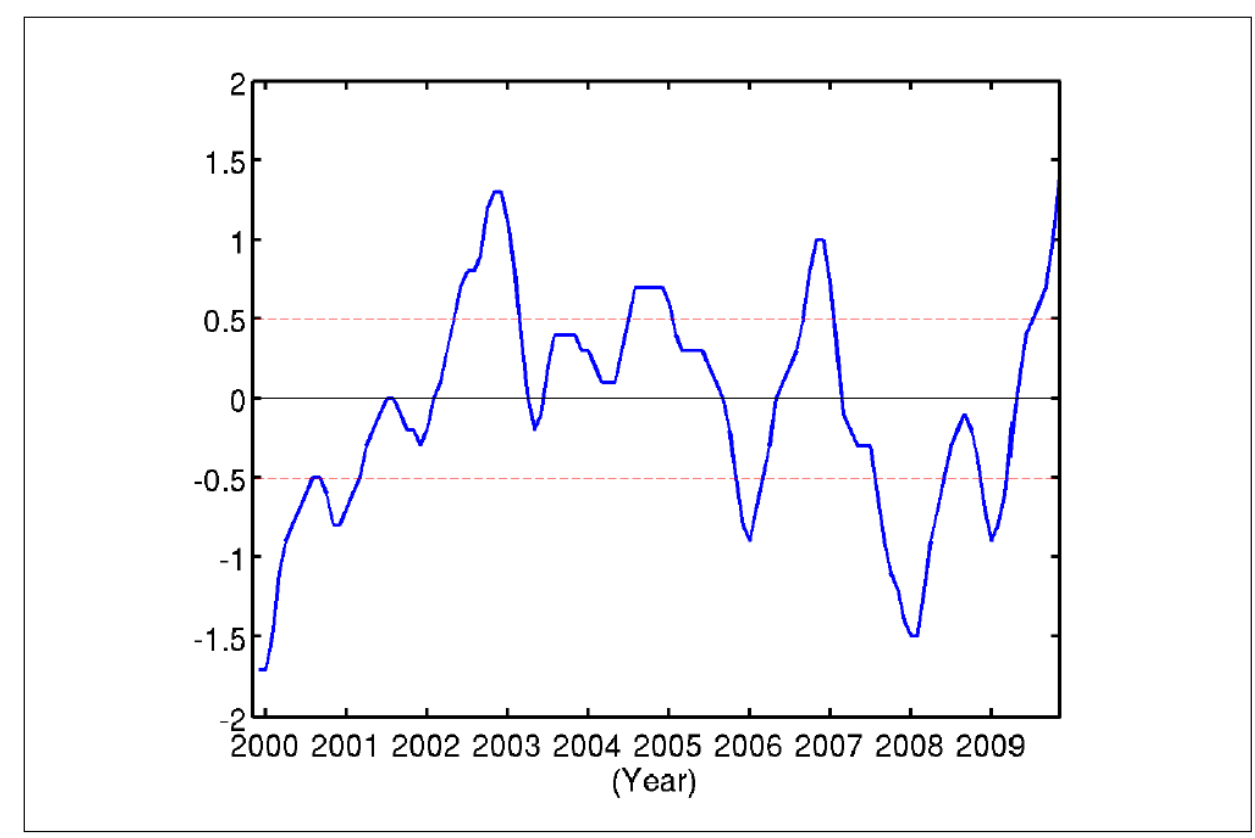

Figure 21. ENSO years based on ONI dataset. SST is at least 0.5 warmer than 30-year average indicate the El Nino. SST is at least 0.5 cooler than 30 -year average indicate the La Nina

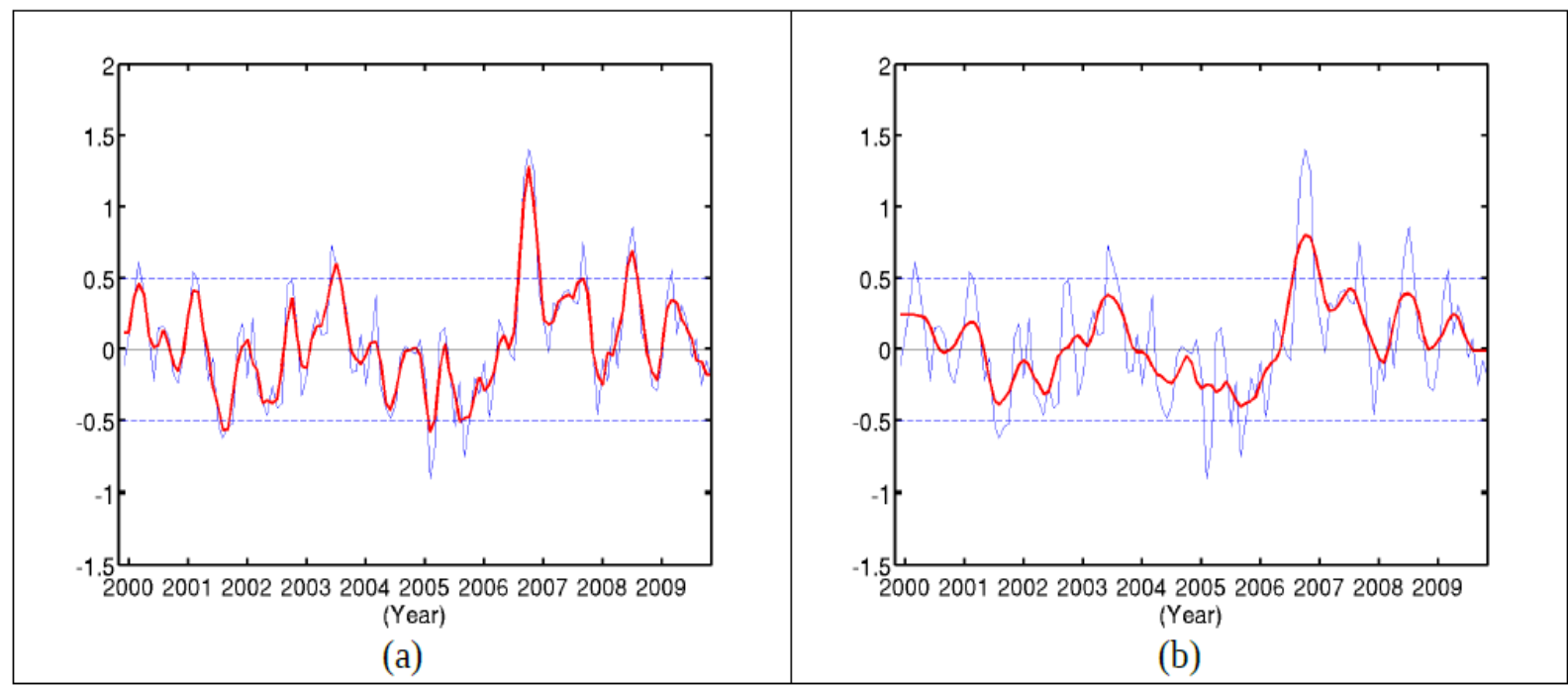

Figure 22. Moving averages of DMI dataset. The 3 months moving averages are shown in panel a; the 6 months moving averages are shown in panel $\mathrm{b}$. The red line indicates the moving averages result and the blue line indicates the original dataset

\section{Acknowledgements}

This research was funded by the DIKNAS Scholarship from the Indonesian Government. We also appreciate the support of JAXA to our research. We express our sincere gratitude to these organizations. We appreciate the enthusiastic support of Prof. Kakuji Ogawara and Dr. Haruma Ishida who helped us make our data scientifically sound. 
We also thank the Remote Sensing Systems for TRMM-TMI and QuikSCAT data; the Earth Observation Research Center, Japan Aerospace Exploration Agency (JAXA EORC) for precipitation data; and the National Oceanic and Atmospheric Administration (NOAA) - Climate Prediction Center (CPC) for ENSO index data; and the Japan Agency for Marine-Earth Science and Technology (JAMSTEC) for IOD index data.

\section{References}

England, M. H., \& Fei, H. (2005). On the interannual variability of the Indonesian throughflow and its linkage with ENSO. J. Clim., 18, 1435-1444. http://dx.doi.org/doi:10.1175/JCLI3322.1

Diaz, H. F., Hoerling, M. P., \& Eischeid, J. K. (2001). ENSO variability, teleconnections and climate change. Int. J. Climatol., 21, 1845-1862. http://dx.doi.org/doi:10.1002/joc.631

Godfrey, J. S. (1996). The effect of the Indonesian throughflow on ocean circulation and heat exchange with the atmosphere: A review. J. Geophys. Res., 101, 12, 217-12, 237. http://dx.doi.org/doi:10.1029/95JC03860

Gordon, A. L., Susanto, R. D., \& Vranes, K. (2003). Cool Indonesian throughflow as a consequence of restricted surface layer flow. Nature, 425, 824-828. http://dx.doi.org/doi:10.1038/nature02038

Gordon, A. L. (2005). Oceanography of the Indonesian seas and their throughflow. Oceanography, 18(4), 14-27. http://dx.doi.org/doi:10.5670/oceanog.2005.01

Gordon, A., Sprintall, J., Van Aken, H. M., Susanto, D., Wijffels, S., Molcard, R., ... Wirasantosa, S., (2010). The Indonesian throughflow during 2004-2006 as observed by the INSTANT program. Dyn. Atmos. Oceans., 50(2), 115-128. http://dx.doi.org/doi:10.1016/j.dynatmoce.2009.12.002

Li, G., Baohua, R., Chengyun, Y., \& Jianqiu, Z. (2010). Indices of El Nino and El Nino Modoki: An improved El Nino Modoki index. Adv. Atmos. Sci., 27(5), 1210-1220.

Luo, J. J., Zhang, R., Swadhin, K. B., Yukio, M., Jin, F. F., Roger, L., \& Toshio, Y. (2010). Interaction between El Nino and Extreme Indian Ocean Dipole. J. Climate, 23, 726-742. http://dx.doi.org/doi:10.1175/2009JCLI3104.1

Nurweda, P. I. D. N., \& Tanaka, T. (2012). Seasonal and inter-annual variability of sea surface temperature and sea surface wind in the eastern part of the Indonesian Sea: ten years analysis of satellite remote sensing data, Proc. SPIE 8525, Remote Sensing of the Marine Environment II, 85250B (December 11, 2012). http://dx.doi.org/doi:10.1117/12.977398

Pradhan, P. K., Preethi, B., Ashok, K., Krishnan, R., \& Sahai, A. K. (2011). Modoki, Indian Ocean Dipole, and western North Pacific typhoons: Possible implications for extreme events. J. Geophys. Res., 116, D18108. http://dx.doi.org/doi:10.1029/2011JD015666

Saji, N. H., Goswami, B. N., Vinayachandran, P. N., \& Yamagata, T. (1999). A dipole mode in the tropical Indian Ocean. Nature, 401, 360-363. http://dx.doi.org/doi:10.1038/43854

Saji, N. H., \& Yamagata, T. (2003). Possible impacts of Indian Ocean Dipole events on global climate. Climate Res., 25, 151-169. http://dx.doi.org/doi:10.3354/cr025151

Smith, W. H. F., \& Sandwell, D. T. (1997). Global seafloor topography from satellite altimetry and ship depth soundings. Science, 277, 1957-1962. http://dx.doi.org/doi:10.1126/science.277.5334.1956

Sprintall, J., Susan, W., Gordon, A. L., Amy, F. R., Molcard, R., Susanto, D., ... van Aken, H. M. (2004). INSTANT: A New International Array to Measure the Indonesian Throughflow. Eos, 85(39), 369-376. http://dx.doi.org/doi: 10.1029/2004EO390002

Susanto, R. D., Moore II, T. S., \& Marra, J. (2006). Ocean color variability in the Indonesia Seas during the $\begin{array}{llllll}\text { SeaWiFS era. Geochemistry, Geophysics, and Geosystems, } & \text { Q05021. }\end{array}$ http://dx.doi.org/doi:10.1029/2005GC001009

Swardika, I. K., Tanaka, T., \& Ishida, H. (2012). Study on the characteristics of the Indonesian Seas using satellite remote-sensing data for 1998-2007. Int. J. of Remote Sensing, 33(8), 2378-2394. http://dx.doi.org/doi:10.1080/01431161.2011.608739

Trenberth, K. E., Branstator, G. W., Karoly, D., Kumar, A., Lau, N. C., \& Ropelewski, C. (1998). Progress during TOGA in understanding and modeling global teleconnections associated with tropical sea surface temperatures. J. Geophys. Res., 103(C7), 14291-14324. http://dx.doi.org/10.1029/97JC01444

Weng, H., Wu, G., Liu, Y., Behera, S. K., \& Yamagata, T. (2009). Anomalous summer climate in China influenced by the tropical Indo-Pacific Oceans. Climate Dynamics., 36(3-4), 769-782 
http://dx.doi.org/doi:10.1007/s00382-009-0658-9

Wyrtki, K. (1962). The upwelling in the region between Java and Australia during the south-east monsoon. Australian Journal of Marine and Freshwater Research, 13(3), 217-225. http://dx.doi.org/doi:10.1071/MF9620217

\section{Copyrights}

Copyright for this article is retained by the author(s), with first publication rights granted to the journal.

This is an open-access article distributed under the terms and conditions of the Creative Commons Attribution license (http://creativecommons.org/licenses/by/3.0/). 